\title{
Characterization of DNA glycosylase activity by matrix-assisted laser desorption/ionization time-of-flight mass spectrometry
}

\author{
Agus Darwanto, Alvin Farrel, Daniel K. Rogstad, and Lawrence C. Sowers ${ }^{*}$ \\ Department of Basic Science, Loma Linda University School of Medicine, Loma Linda, CA 92350, \\ USA
}

\section{Abstract}

The DNA of all organisms is persistently damaged by endogenous reactive molecules. Most of the single-base endogenous damage is repaired through the base excision repair (BER) pathway that is initiated by members of the DNA glycosylase family. Although the BER pathway is often considered to proceed through a common abasic site intermediate, emerging evidence indicates that there are likely distinct branches reflected by the multitude of chemically different 3'- and 5'ends generated at the repair site. In this paper, we have applied matrix-assisted laser desorption/ ionization time-of-flight mass spectrometry (MALDI-TOF-MS) to the analysis of model DNA substrates acted upon by recombinant glycosylases. We examine the chemical identity of several possible abasic site and nicked intermediates generated by monofunctional and bifunctional glycosylases. Our results suggest that the intermediate from endoIII/Nth might not be a simple $\beta$ elimination product as previously described. Upon the basis of ${ }^{18} \mathrm{O}$ incorporation experiments, we propose a new mechanism for the endoIII/Nth family of glycosylases that may resolve several of the previous controversies. We further demonstrate that the use of an array of lesion-containing oligonucleotides can be used to rapidly examine the substrate preferences of a given glycosylase. Some of the lesions examined here can be acted upon by more than one glycosylase, resulting in a spectrum of damaged intermediates for each lesion, suggesting that the sequence and coordination of repair activities that act upon these lesions may influence the biological outcome of damage repair.

\section{Keywords}

DNA glycosylase; MALDI-TOF-MS; oxidative damage; substrate specificity

\section{Introduction}

The DNA of all organisms is persistently damaged and must be continuously repaired. It is estimated that the DNA of higher organisms is damaged between $10^{4}$ and $10^{5}$ times per cell per day under normal physiological conditions, and this number can increase substantially

\footnotetext{
*To whom correspondence should be addressed. Fax: +1 909558 4035. 1sowers@1lu.edu (L.C. Sowers)..

Publisher's Disclaimer: This is a PDF file of an unedited manuscript that has been accepted for publication. As a service to our customers we are providing this early version of the manuscript. The manuscript will undergo copyediting, typesetting, and review of the resulting proof before it is published in its final citable form. Please note that during the production process errors may be discovered which could affect the content, and all legal disclaimers that apply to the journal pertain.
} 
by physiological and chemical stress [1,2]. Most endogenous damage involves single base adducts that are repaired by the base excision repair (BER) pathway. The BER pathway is initiated by one of a series of lesion-selective glycosylases that remove the damaged base [3-6]. The monofunctional glycosylases remove the damaged base generating an abasic site whereas the bifunctional glycosylases generate an abasic site which is then converted directly to a single strand break [7]. The abasic site generated by the monofunctional glycosylases can be converted to a single strand break by AP-endonuclease or by the AP lyase activity of one of the bifunctional glycosylases. Sugar fragments at the repair site are then removed by one of several possible activities, generating a 3'-hydroxyl and a 5'phosphate which serve as the substrate for repair synthesis ending with ligation of the repair gap [8-13].

The endogenous single-base lesions include more than thirty oxidized, hydrolyzed and methylated bases. The glycosylases of the BER pathway generally recognize groups of lesions, exploiting such properties as reduced thermodynamic stability, altered substituent inductive properties, shapes, sizes and hydrogen-bonding properties of functional groups to locate and distinguish damaged from normal bases [14-19]. Although the types of endogenous damage are complex, repair via the BER pathway proceeds through a common abasic site intermediate. Emerging data suggest, however, that there may be sub-pathways through which lesions may be channeled potentially resulting in distinct biological outcomes [20-25].

Experimental studies aimed at examining various steps of BER generally rely upon incubation of oligonucleotides with repair proteins followed by the resolution of ${ }^{32} \mathrm{P}$-labeled fragments by gel electrophoresis [11,12,15-17]. Although well established, gel methods alone cannot reveal the chemical identities of the DNA fragments generated by the BER proteins. Alternatively, analysis by mass spectrometry can provide chemical identification of the repair intermediates. Although MALDI-TOF-MS has been widely applied to the examination of proteins and peptide fragments, substantially less work has been done with oligonucleotides.

In this paper, we designed and synthesized 18-mer oligonucleotides each containing one of a series of eight known endogenous damage products. Each lesion was placed at a defined site so that the masses of the resulting fragments generated by repair proteins would be distinct and resolvable. Oligonucleotides were incubated with BER proteins and examined in parallel by traditional gel methods and by MALDI-TOF-MS. Our results confirm the proposed mechanism of action of most BER proteins examined. However, our results indicate that endoIII/Nth does not generate the expected product of $\beta$-elimination.

Alternatively, we propose a new mechanism that is supported by the results of enzymatic cleavage of oligonucleotides in the presence of ${ }^{18} \mathrm{O}$-enriched water. Our results demonstrate that the intermediates of BER are indeed chemically complex and support suggestions that BER may have multiple sub-pathways. 


\section{Materials and Methods}

\section{Oligonucleotide synthesis and characterization}

Oligonucleotides were prepared by solid-phase synthesis methods as previously described [26]. The sequences of the oligonucleotides used in this study, as well as the modified base of each 18-mer oligonucleotide, are shown in Table 1. The complementary strand for most of the lesions examined here was 5'-TTTCGTGGCCGGCCTCGATT-3' (protonated monoisotopic mass 6,089 amu) in which the damaged or modified pyrimidine was paired opposite G. The complementary strand for the oligonucleotide oxoG was 5'-

TTTCGTGGCCTGCCTCGATT-3' (protonated monoisotopic mass 6,064 amu) in which the oxoG lesion was paired opposite $T$. In all cases, oligonucleotides formed duplexes containing approximately 14 paired bases with potentially unpaired bases at the 3' and 5' duplex ends. The mass of the complementary strand was increased by the addition of terminal bases so that it did not interfere with mass spectral observation of the lesioncontaining oligonucleotides or their fragments.

The phosphoramidites for uracil, 5-fluorouracil, thymine, adenine and guanine, were obtained from Glen Research (Sterling, VA). The phosphoramidites for 5-chlorouracil [27], 5-hydroxymethyluracil [28] and 5-formyluracil [29] were prepared as previously described. Following synthesis, oligonucleotides were deprotected with concentrated aqueous ammonia $\left(28-30 \%\right.$ as $\left.\mathrm{NH}_{3}\right)$ at $60^{\circ} \mathrm{C}$ for $12 \mathrm{~h}$. Oligonucleotides containing potentially labile bases were synthesized using labile protecting groups and deprotected with potassium carbonate in methanol [30]. Oligonucleotides were purified with Poly-Pak II cartridges or by HPLC and further characterized by GC/MS following acid hydrolysis and conversion to the trimethylsilyl ethers [31,32], and also by MALDI-TOF-MS [33,34].

\section{Oligonucleotide labeling and annealing}

5 '-end radiolabeling was performed using Adenosine 5 ' $-\left[\gamma_{-}{ }^{32} \mathrm{P}\right]$ triphosphate $\left(\left[\gamma_{-}{ }^{32} \mathrm{P}\right] \mathrm{ATP}\right)$ (MP Biomedical, Costa Mesa, CA) and T4 polynucleotide kinase (New England BioLabs, Ipswich, MA) under conditions recommended by the enzyme supplier. Labeled mixtures were subsequently centrifuged through G-50 Sephadex columns (Boehringer Mannheim, Indianapolis, IN) to remove excess unincorporated nucleotide. Labeled single-stranded oligonucleotides were annealed to a 2-fold molar excess of unlabeled complementary strand opposite $\mathrm{G}$, except that oxoG was paired with $\mathrm{T}$, in buffer depending on the glycosylase enzyme that we used for the reaction. UNG and endoIII buffer contain $20 \mathrm{mM}$ Tris- $\mathrm{HCl}, 1$ $\mathrm{mM}$ DTT, $1 \mathrm{mM}$ EDTA and $10 \mathrm{mM} \mathrm{MgCl} 2$, pH 8.0; Fpg buffer (10 mM Bis-Tris-Propane$\mathrm{HCl}, 10 \mathrm{mM} \mathrm{MgCl}$, $1 \mathrm{mM}$ DTT, pH 7.0); hOGG1 buffer (10 mM Tris-HCl, $50 \mathrm{mM} \mathrm{NaCl}$, $10 \mathrm{mM} \mathrm{MgCl} 2,1 \mathrm{mM}$ DTT, $\mathrm{pH}$ 7.9); TDG buffer (10 mM HEPES-KOH pH 7.4, $100 \mathrm{mM}$ $\mathrm{KCl}, 10 \mathrm{mM}$ EDTA); MUG buffer (20 mM Tris- $\mathrm{HCl} \mathrm{pH}$ 8.0, $0.1 \mathrm{mg} / \mathrm{ml} \mathrm{BSA}, 1 \mathrm{mM}$ EDTA, $1 \mathrm{mM}$ DTT); hSMUG1 buffer (20 mM Tris-HCl pH 8.0, 1 mM EDTA, 1 mM DTT, $50 \mathrm{mM}$ $\mathrm{NaCl}, 0.1 \mathrm{mg} / \mathrm{ml} \mathrm{BSA}$ ). The mixture was heated to $95^{\circ} \mathrm{C}$ for $1 \mathrm{~min}$ and cooled slowly to room temperature. 


\section{Enzymatic reactions analyzed by gel electrophoresis}

UNG (uracil-DNA glycosylase, E. coli), Fpg (formamidopyrimidine DNA glycosylase, $E$. coli), Nth (Endonuclease III, E. coli) and hOGG1 (human oxoguanine glycosylase 1) were purchased from New England Biolabs (Beverly, MA). MUG (mispaired uracil-DNA glycosylase, E. coli) and TDG (thymine DNA glycosylase, Methanobacterium thermoautotropicum) were obtained from Trevigen (Gaithersburg, MD). hSMUG1 (singlestrand selective monofunctional uracil-DNA glycosylase, human) was cloned and purified by our lab as described previously [35]. DNA substrates (500 fmol/reaction) were incubated with recombinant proteins ( $5 \mathrm{pmol} /$ reaction, except for endoIII, which was at $500 \mathrm{fmol} /$ reaction) for 2 hours at $37{ }^{\circ} \mathrm{C}$ in the reaction buffer depending on the enzyme buffer recommended by the manufacturer in $10 \mu$ total volume. Reactions were stopped by adding $5 \mu \mathrm{l}$ of $0.1 \mathrm{M} \mathrm{NaOH}$ and an equal volume of Maxam-Gilbert loading buffer (98\% formamide, $0.01 \mathrm{M}$ EDTA, $1 \mathrm{mg} / \mathrm{ml}$ xylene cyanol, and $1 \mathrm{mg} / \mathrm{ml}$ bromophenol blue) and 50 pmol modified-base-containing oligonucleotide was added as a competitor. The backbone was cleaved at the apyrimidinic sites with $\mathrm{NaOH}$ by heating at $95^{\circ} \mathrm{C}$ for $30 \mathrm{~min}$ for monofunctional glycosylases (UNG, MUG, TDG and SMUG1). As FoU oligonucleotide is highly labile at higher $\mathrm{pH}$ and temperature, the abasic sites were cleaved by human AP endonuclease 1 (APE1/Ref-1) at $37^{\circ} \mathrm{C}$ for $1 \mathrm{~h}$ in reaction buffer provided by the manufacturer (Trevigen). No further treatment was performed to cleave abasic sites for oligonucleotides treated by endoIII, hOGG1 and Fpg, since they contain apyrimidinic endonuclease activity. Reaction samples were electrophoresed on $18 \%$ denaturing polyacrylamide gels ( $8 \mathrm{M}$ urea), and the bands corresponding to substrate and products were visualized and quantified using a Molecular Dynamics PhosphorImager (Molecular Dynamics, Sunnyvale, CA, now part of GE Healthcare).

\section{Single oligonucleotide-enzyme reactions analyzed by MALDI-TOF-MS}

Each oligonucleotide ( $300 \mathrm{pmol})$ was annealed to a 2 -fold molar excess of the complementary strand in different buffer depending on the reaction buffer of the enzyme. Annealing mixtures were heated to $95^{\circ} \mathrm{C}$ for $1 \mathrm{~min}$ and then cooled down slowly to room temperature. The annealed DNA substrates were incubated with 150 pmol of the enzyme in a total volume of $20 \mu \mathrm{l}$, except endoIII ( $1 \mathrm{pmol} /$ reaction in $30 \mu \mathrm{l}$ total volume). The reactions were performed for $10 \mathrm{~h}$. Furthermore, we characterized cleavage products after base removal by APE1 and $\mathrm{NaOH}$. 300 pmol of $\mathrm{U}$ oligonucleotide was incubated with 150 pmol of UNG in a total volume of $20 \mu \mathrm{l}$; the reactions were performed for $5 \mathrm{~h}$. The reaction products were further treated by APE1 for $3 \mathrm{~h}$ at $37^{\circ} \mathrm{C}$ or $0.1 \mathrm{M} \mathrm{NaOH}$ at $95^{\circ} \mathrm{C}$ for $30 \mathrm{~min}$. The reaction products were desalted using size exclusion micro Bio-spin 6 columns (BioRad, Hercules, CA) as described previously [34]. The columns were rinsed three times with $\mathrm{dH}_{2} \mathrm{O}$ to remove the storage buffer. Residual cations were further exchanged with ammonium ions by incubating with ammonium-form cation exchange AG 50W-X8 beads (BioRad) for $30 \mathrm{~min}$ in a shaker, followed by $30 \mathrm{~min}$ without shaking. Approximately $1 \mu \mathrm{l}$ of matrix solution (10 $\mathrm{g} / 1$ 3-hydroxypicolinic acid [3-HPA] and $1 \mathrm{~g} / \mathrm{l}$ diammonium citrate) was spotted into a 400- $\mu \mathrm{m}$ MTP anchor chip plate (Bruker Daltonics, Billerica, MA) and allowed to dry at room temperature. Approximately $1 \mu \mathrm{l}$ of oligonucleotide sample was then added on to the matrix spot and allowed to dry again at room temperature. Mass spectra 
were examined with a Bruker Autoflex II MALDI-TOF-MS operated in positive ion reflectron mode. The mass calibration standard was composed of a series of oligonucleotides 12, 20 and 30 bases in length (Bruker Daltonics).

\section{Multiple oligonucleotide-enzyme reactions analyzed by MALDI-TOF-MS}

Each of the oligonucleotides, ranging in amount between 200 to 300 pmol, were annealed separately to a 2-fold molar excess of the complementary strand in different buffer depending on the reaction buffer used for the enzyme reactions. Annealed protocols were performed as above. The mixtures of the 8 DNA substrates were incubated with 200 pmol of each enzyme in a total volume of $30 \mu \mathrm{l}$, except endoIII (1.1 pmol/reaction in $40 \mu \mathrm{l}$ total volume). The reactions were performed for $10 \mathrm{~h}$. The reactions and MALDI-TOF-MS analyses were performed as described above.

\section{Borohydrate reduction following enzymatic reactions}

Oligonucleotide ( $300 \mathrm{pmol}$ ) containing $\mathrm{U}$ was incubated with 150 pmol UNG in UNG buffer (as described above) at $37^{\circ} \mathrm{C}$ for $10 \mathrm{~h}$ in $10 \mu \mathrm{l}$ total volume, followed by APE1 (Trevigen, Gitthersburg, MD) treatment at $37^{\circ} \mathrm{C}$ for $3 \mathrm{~h}$ in $10 \mathrm{mM}$ HEPES-KOH (pH 7.4), $100 \mathrm{mM}$ $\mathrm{KCl}, 10 \mathrm{mM} \mathrm{MgCl}$. The reactions were stopped by addition of $300 \mathrm{mM} \mathrm{NaBH}_{4}$ or $\mathrm{NaBD}_{4}$ [36] and then desalted using micro Bio-spin 6 columns (BioRad). Residual cations were exchanged with ammonium ions by incubation with ammonium-form cation exchange AG 50W-X8 beads (Bio-Rad). The MALDI-TOF-MS analyses were performed as described above.

\section{Enzymatic reactions in ${ }^{18} \mathrm{O}$-enriched water}

Oligonucleotide ( $1 \mathrm{nmol}$ ) containing FU was annealed to a 2-fold molar excess of the complementary strand in endoIII buffer as described above. The annealed DNA was added to $5 \mu \mathrm{l}$ of $10 \mathrm{X}$ endoIII buffer, and evaporated using vacuum centrifugation. Then $30 \mu \mathrm{l}$ of $\mathrm{H}^{18}{ }_{2} \mathrm{O}$ (Isotec, West Windsor, NJ) was added and incubated with $20 \mu \mathrm{l}$ endoIII in 50\% glycerol. The reactions were performed at $37^{\circ} \mathrm{C}$ for $14 \mathrm{~h}$. The reaction products were desalted using size exclusion micro Bio-Spin 6 columns (Bio-Rad) as described above. To minimize the glycerol excess, the desalting process using Bio-Spin 6 columns was performed twice. Residual cations were further exchanged with ammonium ions by incubation with ammonium-form cation exchange AG 50W-X8 beads (Bio-Rad). The MALDI-TOF-MS analyses were performed as described above.

\section{Simulation of MALDI-TOF-MS}

The monoisotopic mass of an oligonucleotide with a 3'-deoxyribose phosphate derived from cleavage of the FU-containing oligonucleotide (Table 1) is 3,264.56 ати. The relative heights of the peaks in the isotope cluster can be determined from the molecular formula and the natural abundance of heavier isotopes as described previously [34]. Conducting the reaction in ${ }^{18} \mathrm{O}$-enriched water will increase the mass of the oligonucleotide and alter the relative heights of the peaks in the isotope cluster if an ${ }^{16} \mathrm{O}$ atom is replaced with ${ }^{18} \mathrm{O}$. If the enrichment of the water with ${ }^{18} \mathrm{O}$ is $75 \%$ and one oxygen atom is incorporated from solvent during the enzymatic reaction, $25 \%$ of the molecules will incorporate ${ }^{16} \mathrm{O}$ and $75 \%{ }^{18} \mathrm{O}$. The 
resulting mass spectrum will be a linear combination of the unenriched and enriched oligonucleotides in the ratio 1:3. If two oxygen atoms can be incorporated, an ensemble of molecules will be generated containing zero, one and two ${ }^{18} \mathrm{O}$ atoms in the ratio 1:6:9.

\section{Results}

A series of oligonucleotides was synthesized containing damaged or modified DNA bases including uracil (U), 5-hydroxymethyluracil (HmU), 5-formyluracil (FoU), 8-oxoguanine (oxoG), 5-fluorouracil (FU) and 5-chlorouracil (ClU) as shown in Fig. 1. The oligonucleotides within this series were incubated with several BER proteins, and the resulting oligonucleotide fragments were examined by traditional ${ }^{32} \mathrm{P}-5$ '-end labeling and gel electrophoresis and by MALDI-TOF-MS. The predicted mass of each potential cleavage fragment is presented in Table 1. The glycosylase cleavage efficiency for this series of oligonucleotides is presented in Table 2. The electrophoretic gels corresponding to the data in Table 2 are presented as a supplementary figure (Fig. S1).

The oligonucleotide containing $\mathrm{U}$ was incubated with UNG and examined by gel electrophoresis as shown in Fig. 2. The control oligonucleotide is shown in lane 1, and following incubation with UNG in lane 2. The release of the U base by UNG does not result in backbone cleavage, and therefore there is no apparent change in the oligonucleotide gel mobility. When the oligonucleotide is incubated with UNG and then incubated with alkali (lane 3) or APE1 (lane 4), the backbone is cleaved and fragments with increased, but partially resolvable gel mobility are observed. The gel assay as conducted here allows observation of only the oligonucleotide fragment on the 5'-side of the U. The 5'-fragment generated by APE1 would have a 3'hydroxyl on the 3'-end whereas the fragment generated by alkaline hydrolysis would be expected to have a phosphate group on the 3'-end.

The U-containing oligonucleotide was incubated with UNG as described above and the products were examined by MALDI-TOF-MS. The oligonucleotide containing uracil has a mass of 5,501 ати (Table 1 and Fig. 3A). Cleavage of the $U$ base by UNG, generating an oligonucleotide bearing an abasic site (Fig. 4, II) decreases the observed mass by 94 ати. Loss of $\mathrm{U}$ base would result in a mass decrease of $111 \mathrm{amu}$. However, the monofunctional glycosylases use a water molecule to displace the base resulting in the base moiety being replaced by a hydroxyl group (17 ати) for a net 94 ати mass difference. Although base removal is not observed by gel analysis, the MS analysis allows confirmation that the uracil base, and no other base was removed, and that the base was replaced with a hydroxyl group, confirming the proposed mechanism of action.

Following UNG removal of $U$, the resulting oligonucleotides containing an abasic site were incubated in alkaline solution and with APE1 at neutral $\mathrm{pH}$. The fragment oligonucleotide 5'- to the U residue was observed to be 3,043.6 ати (Fig. 3C) whereas the 5'-fragment generated in alkali was observed to be 3,123.6 ати (Fig 3D). Upon the basis of literature precedent [37] as shown in Fig. 4, the expected 5'-fragment generated by APE1 would contain a 3'-hydroxyl and have a mass of 3,043.6 amu (Fig. 4, III). The 5'-fragment generated in alkali would have a 3'-phosphate and expected mass of 3,123.6 ати (Fig. 4, 
V). The oligonucleotide 5'-fragments observed by MS are therefore consistent with the proposed mechanisms for APE1 and alkaline cleavage, respectively.

Although only the 5'-oligonucleotide fragments are observed in the gel assay, the fragments from both the 5'- and 3'-side of the uracil are observed by MS. Both APE1 and alkali generate fragments of 2,186.4 amu (Fig 3C and D) corresponding to the oligonucleotide fragment 3'- to the uracil residue and containing a phosphate group on its 5'-end (Fig. 4, VIII). It is reported, however, that APE1 generates a 3'-fragment with a 5'-deoxyribose phosphate (5'-dRP), as opposed to the 5'-phosphate observed here [37]. A small peak is observed in the spectrum near the expected mass of the 5'-deoxyribose fragment at 2,382.5 ати (Fig. 5A).

Previous studies [36-38] indicated that the 5'-dRP is chemically unstable and easily degrades to the corresponding phosphate, but it can be stabilized by borohydride reduction. We therefore chemically reduced the product fragments generated by APE1 and examined these products by MS. The oligonucleotide containing the abasic site (5,407 amu, Fig 5A) can be reduced by borohydride increasing the mass to 5,409 ати (Fig. 5B). The 5'-fragment at 3,043.6 ати is unchanged as expected, as is the 3'-fragment with a 5'-phosphate at 2,186.4 ати. A small but increased peak is observed at 2,384.4 amu, corresponding to the chemically reduced (+2 amu) 3'-fragment with a 5'-dRP. In order to confirm this identification, the reduction was repeated with borodeuteride. As expected, the mass of the oligonucleotide containing the abasic site is increased to 5,411 amu, and the mass of the 3'fragment with the 5'-dRP is increased to 2,385.9 amu. These studies confirm that APE1 does generate a 5'-fragment with a 3'-hydroxyl and a 3'-fragment with a 5'-dRP residue. The 5'-dRP fragment $\left(\mathrm{C}_{5} \mathrm{H}_{10} \mathrm{O}_{6} \mathrm{P}, 197 \mathrm{amu}\right)$ is unstable and is lost during sample preparation or analysis, however, it can be observed as a minor product by MALDI-TOFMS following borohydride reduction.

The oxidation of the thymine methyl group can generate the highly mutagenic product FoU. It is known that FoU is removed by multiple glycosylases [16]. Cleavage results using the gel assay with hSMUG1, Fpg and endoIII/Nth are shown in Fig. 2 lanes 5 through 10. hSMUG1 followed by APE1 results in strand cleavage whereas both Fpg and endoIII remove the FoU residue and cleave the phosphate backbone. The electrophoretic mobilities of the cleaved 5'-fragments generated by Fpg and endoIII (Fig. 2, lanes 8 and 10) are different, indicating that the chemical identities of the fragments are different.

Cleavage of the FoU-containing oligonucleotide was also examined by MS. The FoUoligonucleotide has a mass of 5,569 amu (Fig. 6A). hSMUG1 can remove the FoU residue, generating an oligonucleotide containing an abasic site of mass 5,447. Fpg both removes the FoU residue and cleaves the phosphate backbone. The resulting 5'-fragment of mass 3,163.6 is consistent with an oligonucleotide containing a 3'-phosphate (Fig. 4, V) generated by $\beta$ $\delta$-elimination. The 3'-fragment of 2,186.4 ати contains a 5'-phosphate and is a common 3'fragment for this group of oligonucleotides (Fig. 4, VIII).

The FoU residue can also be cleaved by endoIII/Nth followed by phosphate backbone cleavage. The resulting fragments include the common 3'-fragment with a 5'-phosphate 
(2,186.4 атu, Fig. 4, VIII) and the 5'-fragment of mass 3,279.6 amu (Fig. 6D), $116 \mathrm{amu}$ higher than the 5'-fragment generated by Fpg. The 5'-fragments generated by Fpg and endoIII, from the same FoU-oligonucleotide are distinct as indicated by differing gel mobilities and mass. It has been reported that endoIII/Nth acts by $\beta$-elimination, generating a 5'-fragment with a 3'-phosphate connected to a sugar fragment containing an $\alpha-\beta$ unsaturated ketone (Fig. 4, VI) [39-44]. The expected product would have a mass of 3,261.6 ати whereas the observed product, 3,279.6 is 18 mass units heavier and would correspond to a hydration product of the $a-\beta$-unsaturated ketone (Fig. 4, VII).

The mass of the 5'-fragment product generated by endoIII/Nth activity on the FoU oligonucleotide was unexpected. In order to further study this activity, we repeated the experiment with an oligonucleotide containing FU. Gel electrophoresis studies revealed that FU was also a substrate for endoIII/Nth (Fig. S1). As the observed product is $18 \mathrm{amu}$ heavier than the expected product, we repeated the cleavage assay in partially enriched ${ }^{18} \mathrm{O}$ water. The mass spectrum of the 5 '-fragment generated by endoII/Nth on the FU-containing oligonucleotide is shown in Fig. 7D. In panels A, B and C of Fig. 7, the simulated mass spectrum for the 5 '-fragment are shown, assuming the incorporation of no ${ }^{18} \mathrm{O}$ water, one molecule and two molecules of ${ }^{18} \mathrm{O}$ water, respectively. For molecules in this mass range, it is possible to obtain isotope-resolved spectra. Both the observed mass and the mass spectrum are consistent with the incorporation of two water molecules by endoIII into the 5'-fragment. The proposed structure of this fragment is shown in Fig. 4, VII.

Another frequent oxidation product in DNA is oxoG (Fig. 1). In the oligonucleotide duplex prepared here, the oxoG residue was paired opposite thymine. As with FoU, oxoG is removed by multiple activities (Fig. 2, lanes 11-14). Glycosylase activity on the oxoG oligonucleotide generates different 5 '-fragments that are resolvable by gel electrophoresis. The mass of the oxoG oligonucleotide is 5,516 ати (Fig. 8A), and hOGG1 removal of the oxoG residue generates an oligonucleotide containing an abasic site of mass 5,367 ати (Fig. $8 \mathrm{~B})$. The associated lyase activity cleaves the phosphate backbone by $\beta$-elimination $[45,46]$, generating a 5'-fragment with a 3'-phosphate connected to a sugar fragment with an $\alpha-\beta$ unsaturated ketone (Fig. 4, VI) of mass 3,181.5 ати (Fig. 8B). The 3'-fragment is the common 5'-phosphate 2,186.4 amu fragment (Fig 4, VIII). The glycosylase activity is substantially more efficient than the lyase activity as previously reported [46]. The oxoG oligonucleotide is also acted upon by Fpg generating a 3,083.5 ати fragment (Fig. 8C) by $\beta$ - $\delta$-elimination (Fig. 4, V) and the common 3'-phosphorylated product (Fig. 4, VIII). In contrast to hOGG1, Fpg proceeds rapidly from glycosylase to lyase activities.

The above studies, in accord with previous studies, demonstrate that glycosylases usually recognize multiple chemically similar damaged bases. We wished to investigate the possibility of probing the substrate preferences for a given glycosylase when presented with an array of oligonucleotides, each carrying a different modified base. A panel of oligonucleotides was constructed, containing oligonucleotides with $\mathrm{ClU}, \mathrm{C}, \mathrm{U}$, oxoG, T, FU, FoU and HmU. The activity of each of the glycosylases against single substrates was first determined by the standard gel electrophoresis assay (Fig. S1 and Table 2). The sequences of the oligonucleotides were constructed so that each oligonucleotide had a resolvable mass (Table 1). 
The mass spectrum of this ensemble is shown in Fig. 9A. We observed that mixing the oligonucleotides results in decreased resolution, and additional shoulder peaks are apparent resulting from $\mathrm{Na}^{+}$and $\mathrm{K}^{+}$adducts. This ensemble of oligonucleotides was incubated with UNG and the products examined by MS (Fig. 9B). The peaks corresponding to $\mathrm{U}$ and FU have been reduced in intensity, and two additional peaks are observed at lower mass corresponding to the abasic site-containing oligonucleotides generated by removal of $\mathrm{U}$ and $\mathrm{FU}$, denoted by $-\mathrm{U}$ and $-\mathrm{FU}$, respectively. In order to make the differences more apparent, the original mass spectrum (Fig. 9A) was subtracted from the spectrum obtained following incubation with UNG (Fig. 9B) generating a "difference" spectrum, Fig. 9C. The loss of the $\mathrm{U}$ and $\mathrm{FU}$ peaks, and gain of the $-\mathrm{U}$ and $-\mathrm{FU}$ peaks is much more apparent in the difference spectrum. We repeated this experiment with the same panel, but substituting hSMUG1 and TDG for UNG (Fig. 9D and 9E). hSMUG1 and TDG are known to cut most of the modified bases in the panel consistent with the results obtained here. Control oligonucleotides containing $\mathrm{C}$ and $\mathrm{T}$ remain uncut by either glycosylase, as does the oligonucleotide containing oxoG. At present, glycosylase substrate preferences can be examined using the oligonucleotide panel. However, the resolution is not yet sufficient to obtain quantitative data.

\section{Discussion}

Most organisms have developed efficient systems to reverse DNA damage that occurs under normal physiological conditions. The majority of the single base damage is repaired by the base excision repair (BER) pathway that begins with glycosylases that recognize groups of lesions [3-6]. Once the damaged base is removed by the glycosylase activity, lyase or endonuclease activities then cleave the phosphodiester backbone. Additional activities remove sugar fragments left at the lesion site, allowing resynthesis and ligation [8-13]. Substantial current research activities are focused on the mechanisms by which repair proteins recognize damaged DNA, and how various activities work in concert to complete lesion repair.

DNA repair activities have been studied traditionally using ${ }^{32} \mathrm{P}$-labeled oligonucleotides and gel electrophoresis to resolve oligonucleotide products of the various repair activities $[11,12,15-17]$. While these methods have served well to identify significant components of repair pathways, several mechanistic details of BER remain to be unraveled. To further investigate the mechanisms of DNA repair, we have constructed a series of oligonucleotides containing a set of common damaged bases. This ensemble of oligonucleotides has been constructed so that the intact oligonucleotide, and the potential products generated by DNA repair proteins would have resolvable mass when examined by MALDI-TOF-MS. Repair activities were also measured using traditional end-labeling and gel electrophoresis methods for the purpose of comparison.

In the first series of studies, we examined the activities of several monofunctional glycosylases with oligonucleotides containing single modifications. Using the traditional gel assay, oligonucleotides containing an abasic site are generally not resolvable from the parent oligonucleotide as shown in Fig. 2 (lanes 1 and 2). In contrast, glycosylase removal of the damaged base, resulting in the generation of an abasic site-containing oligonucleotide can be 
revealed by MALDI-TOF-MS as shown in Figs 3, 6 and 8. The change in the oligonucleotide mass following incubation with the monofunctional glycosylase corresponds to the loss of the target base and its displacement with a water molecule. These results demonstrate that the specificity of base removal can be established by MS, and data in support of the proposed monofunctional glycosylase mechanism can be generated. Examination of a single oligonucleotide substrate can be extended to an ensemble of oligonucleotides to generate qualitative data on enzyme preferences (Fig. 9). Such studies should prove valuable in quickly examining the substrate selectivity of newly identified activities which can help reveal similarities and differences among glycosylases and suggest mechanisms by which damaged bases are located and distinguished from normal bases.

Following the removal of the damaged base by the glycosylase, the phosphodiester backbone is cleaved by a separate endonuclease in the case of the monofunctional glycosylases, or an associated lyase activity in the case of the bifunctional glycosylases. Traditional gel assays can be used to reveal backbone cleavage. If the gel mobility of the cleavage fragments generated by two different glycosylases are resolvable by gel, it would suggest that the 3'- or 5'-ends of the fragments are chemically different. Analysis by MS can reveal the composition of the oligonucleotide ends generated by the glycosylase/lyase or endonuclease. As an example, the oxidized thymine product, FoU, is cleaved by both Fpg and endoIII/Nth (Figs 2 and 6), generating a 3'-fragment with a 5'-phosphate in both cases, but a 5 '-fragment bearing a $\beta-\delta$-elimination product for $\mathrm{Fpg}$, and an apparent hydrolysis product for endoIII/Nth (3'-deoxyribose phosphate). Further, oxoG is removed by both Fpg and hOGG1 (Figs 2 and 8 ), yielding a $\beta$-elimination product for hOGG1 and a $\beta-\delta$ elimination product for Fpg (3'-phosphate). Although the same damage product can yield multiple repair intermediates, depending upon the glycosylase that acts on the lesion, our results indicate that a given glycosylase yields the same intermediates irrespective of the identity of the original base lesion.

Multiple repair intermediates can be generated during BER, as shown in Fig. 4. In the cases of cleavage by alkali, APE1, Fpg and hOGG1, the products expected upon the basis of literature precedent were confirmed by the MS analysis described here. In the case of endoIII/Nth, a $\beta$-elimination product was anticipated. However, an apparent hydrolysis product was observed by MS. The activity of endoIII was originally described [47] as an "endonuclease" that would generate the 3'-deoxyribose phosphate fragment (Fig. 4, VII). It was demonstrated that the 3 '-ends generated by endoIII could not support polymerase elongation until acted upon by an AP endonuclease that could cleave the blocking 3 'fragment [48]. However, subsequent studies examined the 3'-terminal sugar fragment by chromatographic methods and isotope exchange studies and concluded that endoIII did not act as an endonuclease, but rather as a $\beta$-elimination catalyst [41-44]. Structural studies have revealed that endoIII has a nitrogen nucleophile that acts to displace the base indicating that endoIII, like hOGG1 must act by $\beta$-elimination [49].

In contrast to the previous studies with endoIII discussed above, the studies reported here revealed that the 5'-fragment from endoIII with both FoU and FU carried a 3'-deoxyribose phosphate, and not an $\alpha-\beta$-unsaturated aldehyde fragment as described above. We note that previous MALDI studies on endoIII from different groups similarly observed the same 3'- 
deoxyribose phosphate intermediate reported here with different target lesions [50,51]. We therefore conducted a series of studies with endoIII in the presence of ${ }^{18} \mathrm{O}$-enriched water in order to determine its mechanism of action. If endoIII acted as an endonuclease, we would anticipate the introduction of ${ }^{18} \mathrm{O}$ into the 5 '-phosphate of the 3 '-fragment. No change in mass for the 3'-fragment was observed in the presence of ${ }^{18} \mathrm{O}$ water indicating endoIII does not act by a simple endonuclease mechanism, in accord with the previous literature.

A proposed mechanism that might serve to reconcile the available data is shown in Fig. 10. In the upper panels, structures $\underline{1}$ to $\underline{5}$, the nitrogen nucleophile of a bifunctional glycosylase displaces the damaged base, resulting in a covalent linkage (Schiff base) between the enzyme and the damaged oligonucleotide followed by $\beta$-elimination and backbone cleavage. Subsequent hydrolysis of the oligonucleotide-enzyme complex would release the enzyme, generating the intermediate oligonucleotide with an $a-\beta$-unsaturated aldehyde on the 3 '-end of the 5 '-fragment. In the proposed mechanism for lyases that generate a $\beta$-elimination product, water attacks at the $\mathrm{C} 1$ ' position, resulting in displacement of the enzyme. In the mechanism proposed here for endoIII, the initial water attack could come at the C3'-sugar position, followed by a second water molecule attack at the $\mathrm{C} 1$ '-position resulting in displacement of the enzyme and formation of the 3'-deoxyribose phosphate observed here as shown in Fig. 10, $\underline{6 B}$ to $\underline{8 B}$.

In order to test this hypothesis, we conducted the endoIII cleavage reaction of the FUcontaining oligonucleotide in the presences of ${ }^{18} \mathrm{O}$-enriched water. Oligonucleotides below 5000 ати generally give isotope-resolved spectra by MALDI-TOF-MS. However, for molecules larger than $1000 \mathrm{amu}$, the monoisotopic peak will not be the largest peak. Indeed, the mass spectrum will display a series of peaks, and this series of peaks can be simulated upon the basis of the molecular formula and the abundance of heavier isotopes [34]. The mass spectrum of the 5'-fragment generated by endoIII was simulated for the incorporation of zero, one or two ${ }^{18} \mathrm{O}$ molecules as shown in Fig. 7, A, B and C. The experimentally observed spectrum is shown in Fig. 7D, which matches quite well with the expected spectrum resulting from the incorporation of two ${ }^{18} \mathrm{O}$ molecules.

The MALDI-ToF-MS data presented here, in accord with the data presented by Cadet and coworkers [50,51], indicate that endoIII generates a 5'-fragment with a 3'-deoxyribose phosphate. The mechanism proposed here is consistent with previous studies which suggest that endoIII acts as a lyase, forming an intermediate Schiff base, and that this intermediate would account for isotope exchange from the sugar 2'-position as reported previously. Our results with ${ }^{18} \mathrm{O}$-exchange establish that endoIII does not act as a direct endonuclease, but rather proceeds through a $\beta$-elimination intermediate that acquires two water molecules from solvent for the release of the enzyme.

We can not at this point reconcile our data with previous reports that a sugar fragment was obtained from the 3 '-end of the 5 '-fragment containing an $\alpha-\beta$-unsaturated aldehyde, consistent with a $\beta$-elimination mechanism. We considered the possibility that hydration of the $\alpha-\beta$-unsaturated aldehyde might occur during sample preparation and MALDI-TOF-MS analysis. However, in studies reported here, we did observe the expected $\beta$-elimination product with hOGG1, indicating that this product is observable by the method reported here. 
Conversely, it is known that the deoxyribose phosphate can dehydrate spontaneously forming the $\alpha-\beta$-unaturated aldehyde. Indeed, Fpg and alkaline hydrolysis cleavage proceeds via $\beta$ and then $\delta$-elimination, resulting in formation of the 3 '-phosphate product as observed in this study and a sugar fragment with an $\alpha-\beta$-unsaturated aldehyde. The MALDI-TOF-MS method allows a more direct examination of the repair intermediates, without the need for subsequent enzymatic processing and chromatography, and therefore might provide a more accurate description of the endoIII repair intermediate.

The BER pathway is an essential DNA repair pathway in higher organisms under normal physiological conditions due to the large number and complexity of lesions repaired. Although the BER pathway is often viewed as a means of funneling diverse damage products through a common abasic site intermediate, emerging evidence indicates that BER may contain more complicated sub-pathways through which various lesions formed in different DNA contexts or difference phases of the cell cycle might be channeled, resulting in different biological outcomes. The mechanisms by which lesions are directed through these sub-pathways are not as yet known. However, the chemical structures of the ends of the oligonucleotide fragments generated following cleavage of the abasic site are likely to make a profound difference. Initial cleavage of the abasic site will be either on the 5'-side or 3'-side of the lesion, and ultimately, unobstructed 3'-hydroxyl and 5'-phosphate ends are required for repair synthesis and ligation. Monofunctional glycosylase cleavage of the damaged DNA base is generally followed by AP endonuclease, generating a 3'-hydroxyl and a 5'-deoxyribose phosphate [5-7,52]. The bifunctional glycosylases, with their associated lyase activities, cleave the abasic site on the opposite 3 '-side, generating a 5'phosphate and either a 3'-phosphate, 3'-deoxyribose phosphate, or 3'-phosphate with a remnant $a-\beta$-unsaturated aldehyde $[7,52]$. The 5 '-deoxyribose phosphate fragment generated by APE1 blocks ligation if not removed whereas any of the 3'-substituents generated by the bifunctional glycosylases block DNA polymerase $[7,52,53]$.

If the lesion is acted upon by a monofunctional glycosylase followed by APE1, the 5'deoxyribose phosphate can be removed by a lyase activity of pol $\beta$, resulting in repair synthesis ligation and completion of the short-patch sub-pathway [7,52,53]. However, if the 5 '-deoxyribose phosphate is oxidized, forming the corresponding 2-deoxyribonolactone phosphate, additional polymerases might engage the repair site, and long-patch repair will ensue [7,54]. There is growing evidence that the presence of the 5'-deoxyribose phosphate increases the affinity of the short-patch repair proteins and that persistence of the 5'deoxyribose phosphate might be important in signaling DNA damage [53,54].

If the lesion is acted upon by a bifunctional glycosylase, an unobstructed 5'-phosphate is generated, but the 3'-hydroxyl is blocked. The 3'-phosphate generated by $\beta-\delta$-elimination can be removed by polynucleotide kinase (PNK), allowing repair synthesis to proceed, whereas the $a-\beta$-unsaturated aldehyde generated by $\beta$-elimination requires removal by APE. The potential for clearing a 3'-phosphate by PNK, constitutes an "APE independent" repair sub-pathway $[52,55]$. The 3 '-dRP generated by endoIII/Nth described here is apparently removed by APE as well [48]. However, the impact of the 3'-dRP on further repair kinetics and protein complex formation has not yet been studied. 
Some of the lesions here can be acted upon by multiple glycosylases, resulting in a complex transit through BER. For example, uracil is acted upon by multiple glycosylases and the lesion is processed potentially through any of the pathways described here. The repair of uracil can proceed through error correction pathways, or it can result in somatic hypermutation and class-switch recombination in activated B-cells [24, 25], illustrating how the selection of the repair pathway can profoundly influence the physiological outcome of the repair process. Although the mechanism for sub-pathway selection is unknown, it is known that the human monofunctional glycosylases SMUG1 and TDG have substantially higher affinity for the abasic site than UNG, and stay bound to the intermediate abasic site until displaced by APE1, influencing the selection of further steps in the repair pathway $[35,56,57]$. The data presented here demonstrate the utility of MALDI-ToF-MS in elucidating the structures of intermediates generated by BER proteins. The results of the studies reported here illustrate the complexity of the BER pathway and demonstrate an important role of MALDI-TOF-MS in resolving important structural and mechanistic questions.

\section{Acknowledgments}

This work was supported by funds from the National Institutes of Health, National Cancer Institute and National Institute of General Medical Sciences.

\section{Abbreviations}

MALDI-TOF-MS

BER

AP

UNG

MUG

TDG

hSMUG1

APE1

hOGG1

Nth

Fpg

HEPES-KOH

DTT

EDTA

BSA matrix-assisted laser desorption/ionization time-of-flight mass

spectrometry

base excision repair

apurinic/apyrimidinic

uracil-DNA glycosylase

mispaired uracil-DNA glycosylase

thymine-DNA glycosylase

human single-strand selective monofunctional uracil-DNA

glycosylase 1

AP endonuclease 1

human oxoguanine glycosylase 1

E. coli endonuclease III

formamidopyrimidine DNA glycosylase

4-(2-hydroxyethyl)-1-piperazineethanesulfonic acid

dithiothreitol

ethylenediaminetetraacetic acid

bovine serum albumin 


$\begin{array}{ll}\text { 3-HPA } & \text { 3-hydroxypicolinic acid } \\ \text { GC-MS } & \text { gas chromatography-mass spectrometry } \\ \text { HPLC } & \text { high-performance liquid chromatography } \\ {\left[\gamma_{-}^{-32} \text { P]ATP }\right.} & \text { Adenosine }{ }^{\prime}-{ }^{-}{ }^{32}{ }^{2} \text { P]triphosphate } \\ \text { G } & \text { guanine } \\ \text { C } & \text { cytosine } \\ \text { T } & \text { thymine } \\ \text { U } & \text { uracil } \\ \text { FU } & \text { 5-fluorouracil } \\ \text { CIU } & \text { 5-chlorouracil } \\ \text { FoU } & \text { 5-formyluracil } \\ \text { HmU } & \text { 5-hydroxymethyluracil } \\ \text { oxoG } & \text { 8-oxoguanine } \\ \text { PNK } & \text { polynucleotide kinase } \\ \text { 3'-dRP } & \text { 3'-deoxyribose phosphate }\end{array}$

\section{References}

1. Mullart E, Lohman PHM, Berends F, Vijg J. DNA damage metabolism and aging. Mutat. Res. 1990; 237:189-210. [PubMed: 2079959]

2. Lindhal T. Instability and decay of the primary structure of DNA. Nature. 1993; 362:709-715. [PubMed: 8469282]

3. Slupphaug G, Eftedal I, Kavli B, Bharati S, Helle NM, Haug T, Levine DW, Krokan HE. Properties of a recombinant human uracil-DNA glycosylase from the $U N G$ gene and evidence that $U N G$ encodes the major uracil-DNA glycosylase. Biochem. 1995; 34:128-138. [PubMed: 7819187]

4. Jaiswal M, Lipinski LJ, Bohr VA, Mazur SJ. Efficient in vitro repair of 7-hydro-8oxodeoxyguanosine by human cell extracts: involvement of multiple pathways. Nucleic Acids Res. 1998; 26:2184-2191. [PubMed: 9547279]

5. Pearl LH. Structure and function in the uracil-DNA glycosylase superfamily. Mutat. Res. 2000; 460:165-181. [PubMed: 10946227]

6. Krokan HE, Nilsen H, Skorpen F, Otterlei M, Slupphaug G. Base excision repair of DNA in mammalian cells. FEBS Lett. 2000; 476:73-77. [PubMed: 10878254]

7. Ide H, Kotera M. Human DNA glycosylases involved in the repair of oxidatively damaged DNA. Biol. Pharm. Bull. 2004; 27:480-485. [PubMed: 15056851]

8. Prasad R, Beard WA, Strauss PR, Wilson SH. Human DNA polymerase $\beta$ deoxyribose phosphate lyase. J. Biol. Chem. 1998; 273:15263-15270. [PubMed: 9614142]

9. Mosbaugh DW, Linn S. Further characterization of human fibroblast apurinic/apyrimidinic DNA endonucleases. J. Biol. Chem. 1980; 255:11743-11752. [PubMed: 6254980]

10. Franklin WA, Lindahl T. DNA deoxyribophosphodiesterase. EMBO J. 1988; 7:3617-3622. [PubMed: 2850170]

11. Pascucci B, Maga G, Hubscher U, Bjoras M, Seeberg E, Hickson ID, Villani G, Giordano C, Cellai L, Dogliotti E. Reconstitution of the base excision repair pathway for 7,8-dihydro-8-oxoguanine with purified human proteins. Nucleic Acids Res. 2002; 30:2124-2130. [PubMed: 12000832] 
12. Vidal AE, Hickson ID, Boiteux S, Radicella JP. Mechanism of stimulation of the DNA glycosylase activity of hOGG1 by the major human AP endonuclease: bypass of the AP lyase activity step. Nucleic Acids Res. 2001; 29:1285-1292. [PubMed: 11238994]

13. McCullough AK, Dodson ML, Lloyd RS. Initiation of base excision repair: glycosylase mechanisms and structures. Annu. Rev. Biochem. 1999; 68:255-285. [PubMed: 10872450]

14. Singer B, Hang B. What structural features determine repair enzyme specificity and mechanism in chemically modified DNA?. Chem. Res. Toxicol. 1997; 10:713-732. [PubMed: 9250405]

15. Liu P, Burdzy A, Sowers LC. Substrate recognition by a family of uracil-DNA glycosylases: UNG, MUG, TDG. Chem. Res. Toxicol. 2002; 15:1001-1009. [PubMed: 12184783]

16. Liu P, Burdzy A, Sowers LC. Repair of the mutagenic DNA oxidation product, 5-formyluracil. DNA Repair. 2003; 2:199-210. [PubMed: 12531390]

17. Liu P, Theruvathu JA, Darwanto A, Lao VV, Pascal T, Goddard W III, Sowers LC. Mechanisms of base selection by the E. coli mispaired uracil glycosylase. J. Biol. Chem. 2008; 283:8829-8836. [PubMed: 18208817]

18. Bennett MT, Rodgers MT, Hebert AS, Ruslander LE, Eisele L, Drohat AC. Specificity of human thymine DNA glycosylase depends on N-glycosidic bond stability. J. Am. Chem. Soc. 2006; 128:12510-12519. [PubMed: 16984202]

19. Liu Y, Prasad R, Beard WA, Kedar PA, Hou EW, Shock DD, Wilson SH. Coordination of steps in single-nucleotide base excision repair medicated by apurinic/apyrimidinic endonuclease 2 and DNA polymerase $\beta$. J. Biol. Chem. 2007; 282:13532-13541. [PubMed: 17355977]

20. Ischenko AA, Saparbaev MK. Alternative nucleotide incision repair pathway for oxidative DNA damage. Nature. 2002; 415:183-187. [PubMed: 11805838]

21. Wiederhold L, Leppard JB, Kedar P, Karimi-Busheri F, Rasouli-Nia A, Weinfeld M, Tomkinson AE, Izumi T, Prasad R, Wilson SH, Mitra S, Hazra TK. AP endonuclease-independent DNA base excision repair in human cells. Mol. Cell. 2004; 15:209-220. [PubMed: 15260972]

22. Sung J-K, Demple B. Roles of base excision repair subpathways in correcting oxidized abasic sites in DNA. FEBS J. 2006; 273:1620-1629. [PubMed: 16623699]

23. Shen HM, Tanaka A, Bozek G, Nicolae D, Storb U. Somatic hypermuation and class switch recombination in $\mathrm{Msh}^{-/} \mathrm{Ung}^{-/-}$double-knockout mice. J. Immunology. 2006; 177:5386-5392. [PubMed: 17015724]

24. Pettersen HS, Sundheim O, Gilljam KM, Slupphaug G, Krokan HE, Kavli B. Uracil-DNA glycosylases SMUG1 and UNG2 coordinate the initial steps of base excision repair by distinct mechanisms. Nucleic Acids Res. 2007; 35:3879-3892. [PubMed: 17537817]

25. Di Noia JM, Williams GT, Chan DTY, Buerstedde J-M, Baldwin GS, Neuberger MS. Dependence of antibody gene diversification on uracil excision. J. Exper. Med. 2007; 204:3209-3219. [PubMed: 18070939]

26. Gait, MJ. Oligonucleotide Synthesis: a practical approach. Oxford, IRL Press; Washington DC: 1984.

27. Brandon ML, Mi L-J, Chaung W, Teebor G, Boorstein RJ. 5-chloro-2'-deoxyuridine cytotoxicity results from base excision repair of uracil subsequent to thymidylate synthase inhibition. Mutat. Res. 2000; 459:161-169. [PubMed: 10725666]

28. Sowers LC, Beardsley GP. Synthesis of oligonucleotides containing 5-(hydroxymethyl)-2'deoxyuridine at defined sites. J. Org. Chem. 1993; 58:1664-1665.

29. Berthod T, Petillot Y, Guy A, Cadet J, Forest E, Molko D. Synthesis and mass spectrometry analysis of oligonucleotides bearing 5-formyl-2'-deoxyuridine in their structure. Nucleosides Nucleotides. 1996; 15:1287-1305.

30. Kuijpers WHA, Kuyl-Yeheskiely E, van Boom JH, van Boeckel CAA. The application of the AMB protective group in the solid-phase synthesis of methylphosphonate DNA analogues. Nucleic Acids Res. 1993; 21:3493-3500. [PubMed: 8346028]

31. Dizdaroglu M. Facts about the artifacts in the measurement of oxidative DNA base damage by gas chromatography-mass spectrometry. Free Rad. Res. 1998; 29:551-563.

32. LaFrancois CJ, Yu K, Sowers LC. Quantification of 5-(hydroxymethyl)uracil in DNA by gas chromatography/mass spectrometry: problems and solutions. Chem. Res. Toxicol. 1998; 11:786793. [PubMed: 9671541] 
33. Pan C, Xu S, Houjiang Z, Fu Y, Ye M, Zou H. Recent developments in methods and technology for analysis of biological samples by MALDI-TOF-MS. Anal. Bioanal. Chem. 2007; 387:193204. [PubMed: 17086385]

34. Cui Z, Theruvathu JA, Farrel A, Burdzy A, Sowers LC. Characterization of synthetic oligonucleotides containing biologically important modified bases by matrix-assisted laser desorption/ionization time-of-flight mass spectrometry. Anal. Biochem. 2008; 379:196-207. [PubMed: 18485883]

35. Haushalter KA, Stukenber PT, Kirschner MW, Verdine GL. Identification of a new uracil-DNA glycosylase family by expression cloning using synthetic inhibitors. Curr. Biol. 1999; 9:174-185. [PubMed: 10074426]

36. Wong E, Demple B. Modulation of the 5'-deoxyribose-5-phosphate lyase and DNA synthesis activities of mammalian DNA polymerase $\beta$ by apurinic/apyrimidinic endonuclease 1. J. Biol. Chem. 2004; 279:25268-25275. [PubMed: 15078879]

37. Hill JW, Hazra TK, Izumi T, Mitra S. Stimulation of human 8-oxoguanine-DNA glycosylase by AP-endonuclease: potential coordination of the initial steps in base excision repair. Nucleic Acids Res. 2001; 29:430-438. [PubMed: 11139613]

38. Marenstein DR, Chan MK, Altamirano A, Basu AK, Boorstein RJ, Cunningham RP, Teebor GW. Substrate specificity of human endonuclease III (hNTH1), effect of human APE1 on hNTH1 activity. J. Biol. Chem. 2003; 278:9005-9012. [PubMed: 12519758]

39. Zharkov DO, Rieger RA, Iden CR, Grollman AP. NH2-terminal proline acts as a nucleophile in the glycosylase/AP-lyase reaction catalyzed by E. coli formamidopyrimidine-DNA glycosylase (Fpg) protein. J. Biol. Chem. 1997; 272:5335-5341. [PubMed: 9030608]

40. Bhagwat M, Gerlt JA. 3'-and 5'-strand cleavage catalyzed by the Fpg protein from E. coli occur via successive $\beta$ - and $\delta$-elimination mechanisms, respectively. Biochem. 1996; 35:659-665. [PubMed: 8555240]

41. Kim J, Linn S. The mechanisms of action E. coli endonuclease III and T4 UV endonuclease (endonuclease V) at AP sites. Nucleic Acids Res. 1988; 16:1135-1141. [PubMed: 2449657]

42. Bricteux-Gregoire S, Verly WG. The use of the thioglycolate to distinguish between 3' AP (apurinic/apyrimidinic) endonucleases and AP lyases. Nucleic Acids Res. 1989; 17:6269-6282. [PubMed: 2475855]

43. Bailly V, Verly WG. E. coli endonuclease III is not an endonuclease but a $\beta$-elimination catalyst. Biochem. J. 1987; 242:565-572. [PubMed: 2439070]

44. Mazumder A, Gerlt JA. Stereochemical studies of the $\beta$-elimination reactions at aldehydic abasic sites in DNA: endonuclease III from E. coli, sodium hydroxide, and Lys-Trp-Lys. Biochem. 1991; 30:1119-1126. [PubMed: 1846560]

45. van der Kemp PA, Thomas D, Barbey R, de Oliveira R, Boiteux S. Cloning and expression in E. coli of the OGG1 gene of Saccharomyces cerevisiae, which codes for a DNA glycosylase that excises 7,8-dihydro-8-oxoguanine and 2,6-diamino-4-hydroxy-5- $N$-methylformamidopyrimidine. Proc. Natl. Acad. Sci. USA. 1996; 93:5197-5202. [PubMed: 8643552]

46. Bjoras M, Luna L, Johnsen B, Hoff E, Haug T, Rognes T, Seeberg E. Opposite base-dependent reactions of a human base excision repair enzyme on DNA containing 7,8-dihydro-8-oxoguanine and abasic sites. EMBO J. 1997; 16:6314-6322. [PubMed: 9321410]

47. Warner HR, Demple BF, Deutsch WA, Kane CM, Linn S. Apurinic/apyrimidinic endonucleases in repair of pyrimidine dimers and other lesions in DNA. Proc. Natl. Acad. Sci. USA. 1980; 77:4602-4606. [PubMed: 6254032]

48. Piersen CE, McCullough AM, Lloyd RS. AP lyases and dRPases: commonality of mechanism. Mutat. Res. 2000; 459:43-53. [PubMed: 10677682]

49. Ikeda S, Biswas T, Roy R, Izumi T, Boldogh I, Kurosky A, Sarker AH, Mitra S. Purification and characterization of human NTH1, a homolog of E. coli endonuclease III. J. Biol. Chem. 1998; 273:21585-21593. [PubMed: 9705289]

50. D'Ham C, Romieu A, Jaquinod M, Gasparutto D, Cadet J. Excision of 5,6-dihydroxy-5,6dihydrothymine, 5,6-dihydrothymine, and 5-hydroxycytosine from defined sequence oligonucleotides by E. coli endonuclease III and Fpg Proteins: kinetic and mechanistic aspects. Biochem. 1999; 38:3335-3344. [PubMed: 10079077] 
51. Duarte V, Gasparutto D, Jaquinod M, Cadet J. In vitro DNA synthesis opposite oxazolone and repair of this DNA damage using modified oligonucleotides. Nucleic Acids Res. 2000; 28:15551563. [PubMed: 10710422]

52. Hegde ML, Hazra T, Mitra S. Early steps in the DNA base excision/single-strand interruption repair pathway in mammalian cells. Cell Res. 2008; 18:27-47. [PubMed: 18166975]

53. Sobol RW, Prasad R, Evenski A, Baker A, Yang X-P, Horton JK, Wilson SH. The lyase activity of the DNA repair protein $\beta$-polymerase protects from DNA-damage-induced cytotoxicity. Nature. 2000; 405:807-810. [PubMed: 10866204]

54. Fortini P, Pascucci B, Parlanti E, Sobol RW, Wilson SH, Doglitti E. Different DNA polymerases are involved in the short- and long-patch base excision repair in mammalian cells. Biochem. 1998; 37:3575-3580. [PubMed: 9530283]

55. Ali MM, Hazra TK, Hong D, Kow YW. Action of human endonucleases III and VIII upon DNAcontaining tandem dihydrouracil. DNA Repair. 2005; 4:679-686. [PubMed: 15907775]

56. Wibley JEA, Waters TR, Haushalter K, Verdine GL, Pearl LH. Structure and specificity of the vertebrate anti-mutator uracil-DNA glycosylase SMUG1. Mol. Cell. 2003; 11:1647-1659. [PubMed: 12820976]

57. Hardeland U, Steinacher R, Jiricny J, Schar P. Modification of the human thymine-DNA glycosylase by ubiquitin-like proteins facilitates enzymatic turnover. EMBO J. 2002; 21:14561464. [PubMed: 11889051] 
<smiles>Nc1cc[nH]c(=O)n1</smiles><smiles>Cc1c[nH]c(=O)[nH]c1=O</smiles><smiles></smiles><smiles>O=c1[nH]cc(F)c(=O)[nH]1</smiles>

FU<smiles>O=c1[nH]cc(Cl)c(=O)[nH]1</smiles><smiles>O=Cc1c[nH]c(=O)[nH]c1=O</smiles>

CIU<smiles>O=c1[nH]cc(CO)c(=O)[nH]1</smiles>

$\mathrm{HmU}$<smiles></smiles>

OXOG

Fig. 1.

Structures of natural and modified bases, C (Cytosine), T (Thymine), U (Uracil), FU (5fluorouracil), ClU (5-chlorouracil), FoU (5-formyluracil), HmU (5-hydroxymethyluracil) and oxoG (8-oxoguanine). 


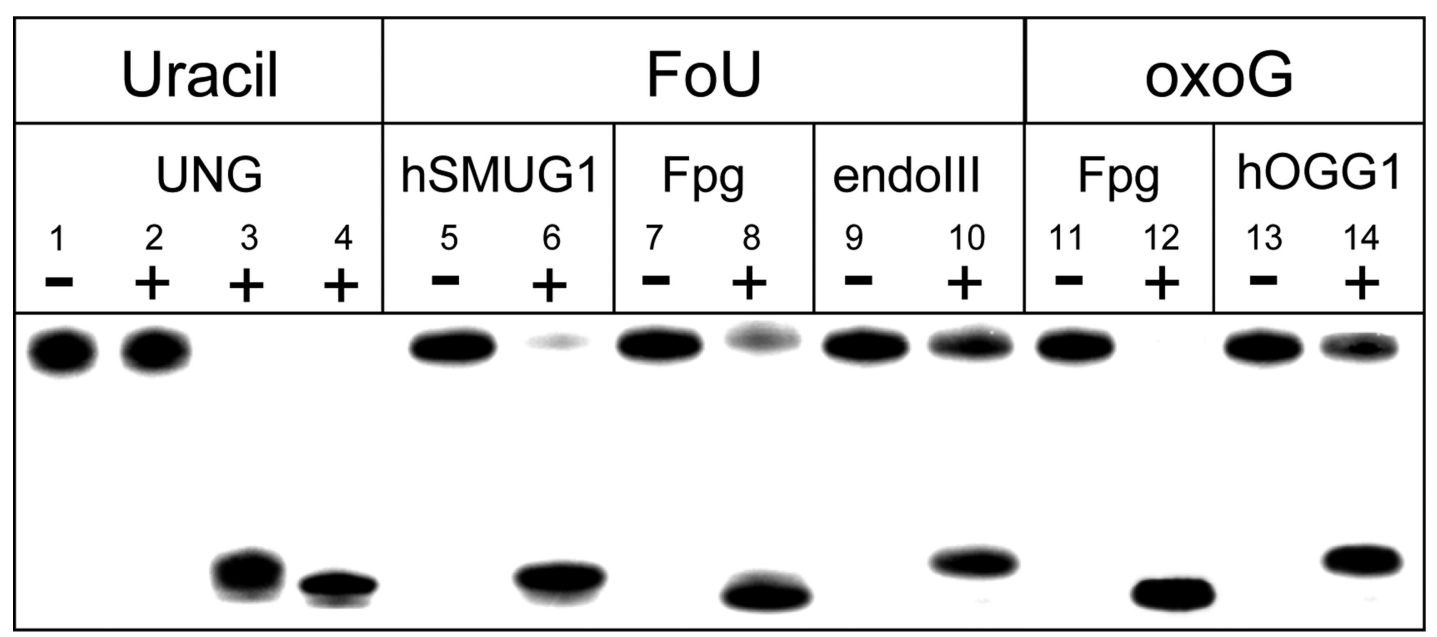

Fig. 2.

Gel electrophoretic profiles of substrate specificity of glycosylases. The oligonucleotide containing $\mathrm{U}$ was incubated with UNG followed by $\mathrm{NaOH}$ (lane 3) or APE1 (lane 4). The oligonucleotide containing FoU was incubated with hSMUG1 followed by APE1 (lane 6), Fpg (lane 8) and endoIII (lane 10). The oligonucleotide containing oxoG was incubated with Fpg (lane 12) and hOGG1 (lane 14). 

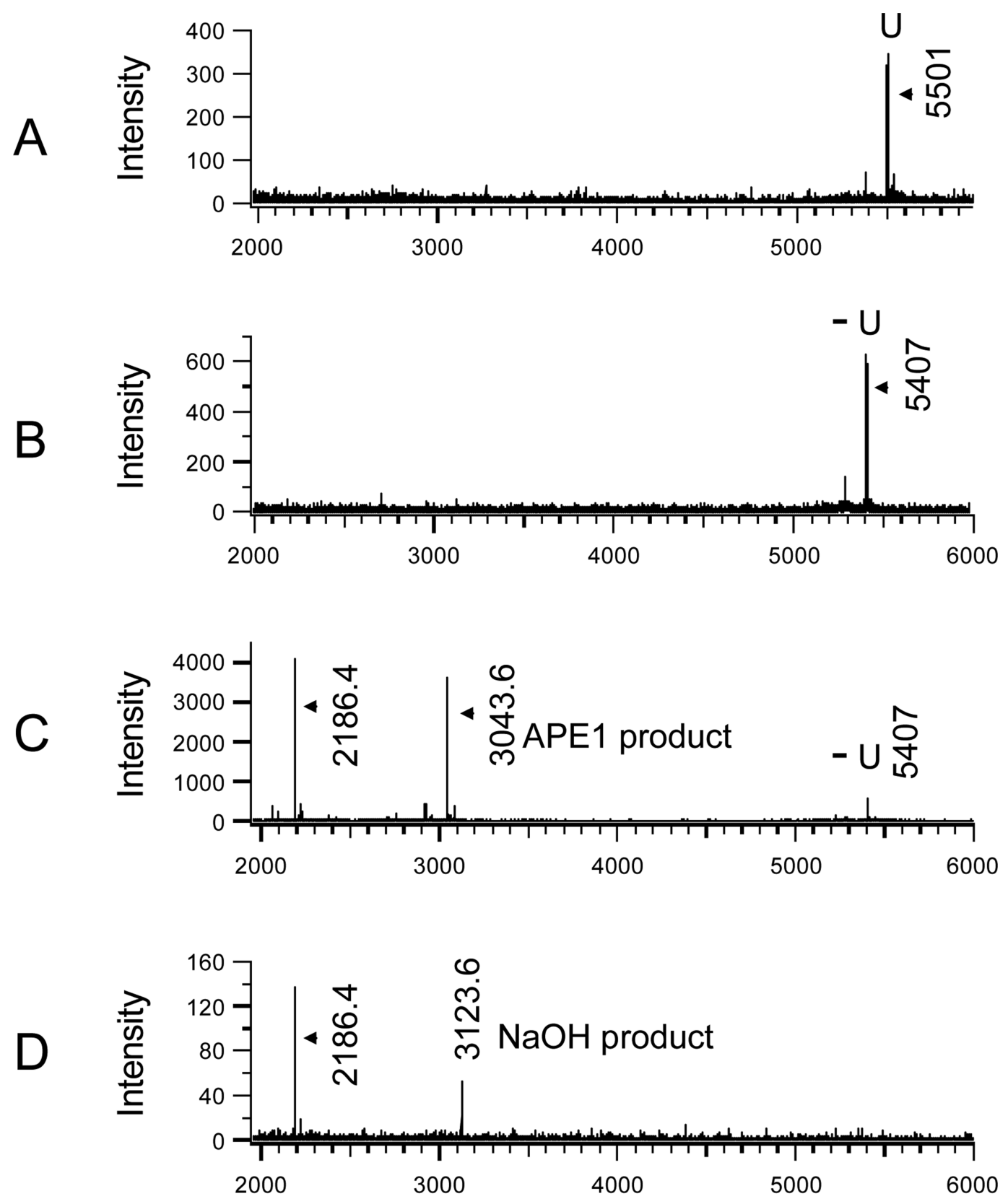

$\mathrm{m} / \mathrm{z}$

Fig. 3.

Characterization of cleavage products of 18-mer oligonucleotide containing uracil (U) by UNG, followed by APE1 or $\mathrm{NaOH}$ treatment. A) Uncut oligonucleotide containing U, B) Oligonucleotide containing U cut by UNG with loss of uracil base, C) Oligonucleotide containing $\mathrm{U}$ cut with UNG followed by APE1, D) Oligonucleotide containing $\mathrm{U}$ cut by UNG followed by alkali. The observed monoisotopic mass values are reported to one decimal place for low molecular mass oligonucleotides, but for higher molecular masses, are reported as integer values due to the inherent lower resolution at high mass. 


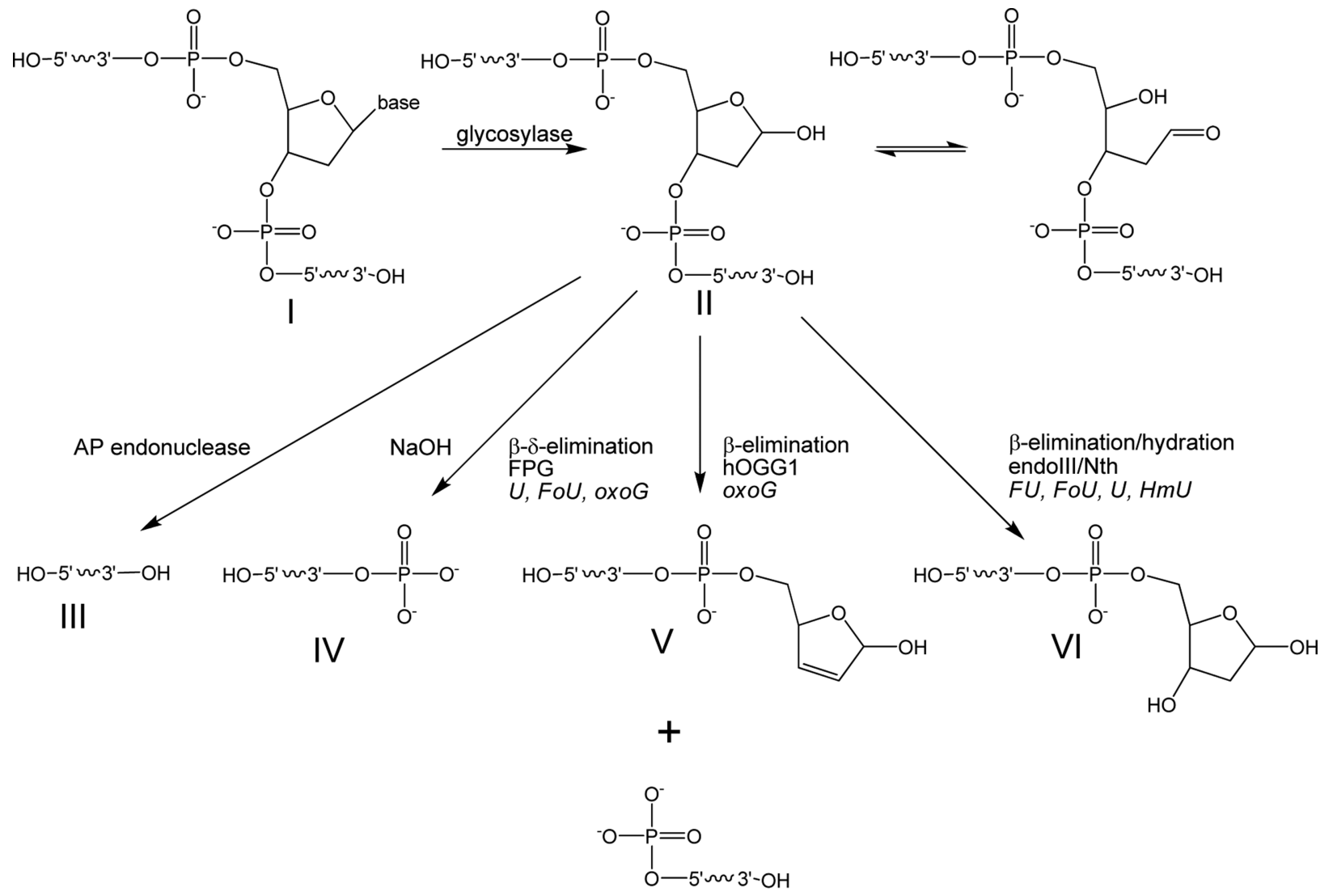

VII

Fig. 4.

Schematic representation of the expected oligonucleotide release products by reactions mediated by glycosylases, according to different mechanisms of phosphodiester bond cleavage. Lesions acted upon by repair activities listed on the figure are shown in italics. For example, oligonucleotide containing U (I) could be processed by UNG (resulting in II), followed by AP Endonuclease (converting II to III + IV) and finally pol $\beta$ (sugar moiety removed, converting IV into VIII). 

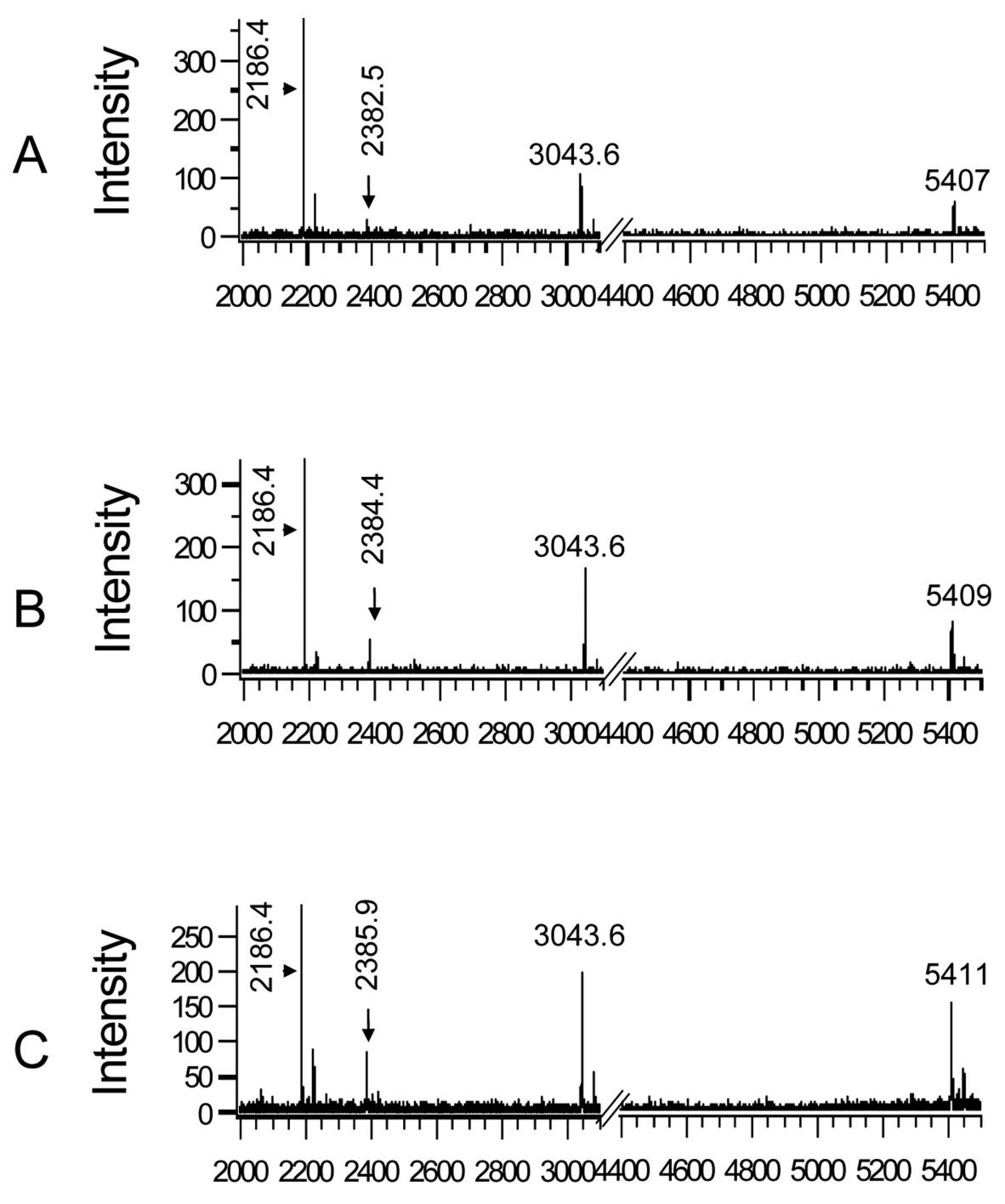

$\mathrm{m} / \mathrm{z}$

Fig. 5.

Cleavage of uracil-containing oligonucleotide with UNG followed by APE1 treatment. A) Cleavage under standard conditions, B) UNG cleavage followed by $\mathrm{NaBH}_{4}$ : Note peaks at 5409 and 2384.4 resulting from reduction of abasic site-containing oligonucleotide and the cleaved oligonucleotide containing a 5'-deoxyribose phosphate, C) UNG cleavage followed by $\mathrm{NaBD}_{4}$ in which the reduced forms of the abasic site and 5-deoxyribose phosphate are increased in mass by two units. $\mathrm{C}_{5} \mathrm{H}_{10} \mathrm{O}_{6} \mathrm{P}=197 \mathrm{amu}$. The observed monoisotopic mass values are reported to one decimal place for low molecular mass oligonucleotides, but for higher molecular masses, are reported as integer values due to the inherent lower resolution at high mass. 

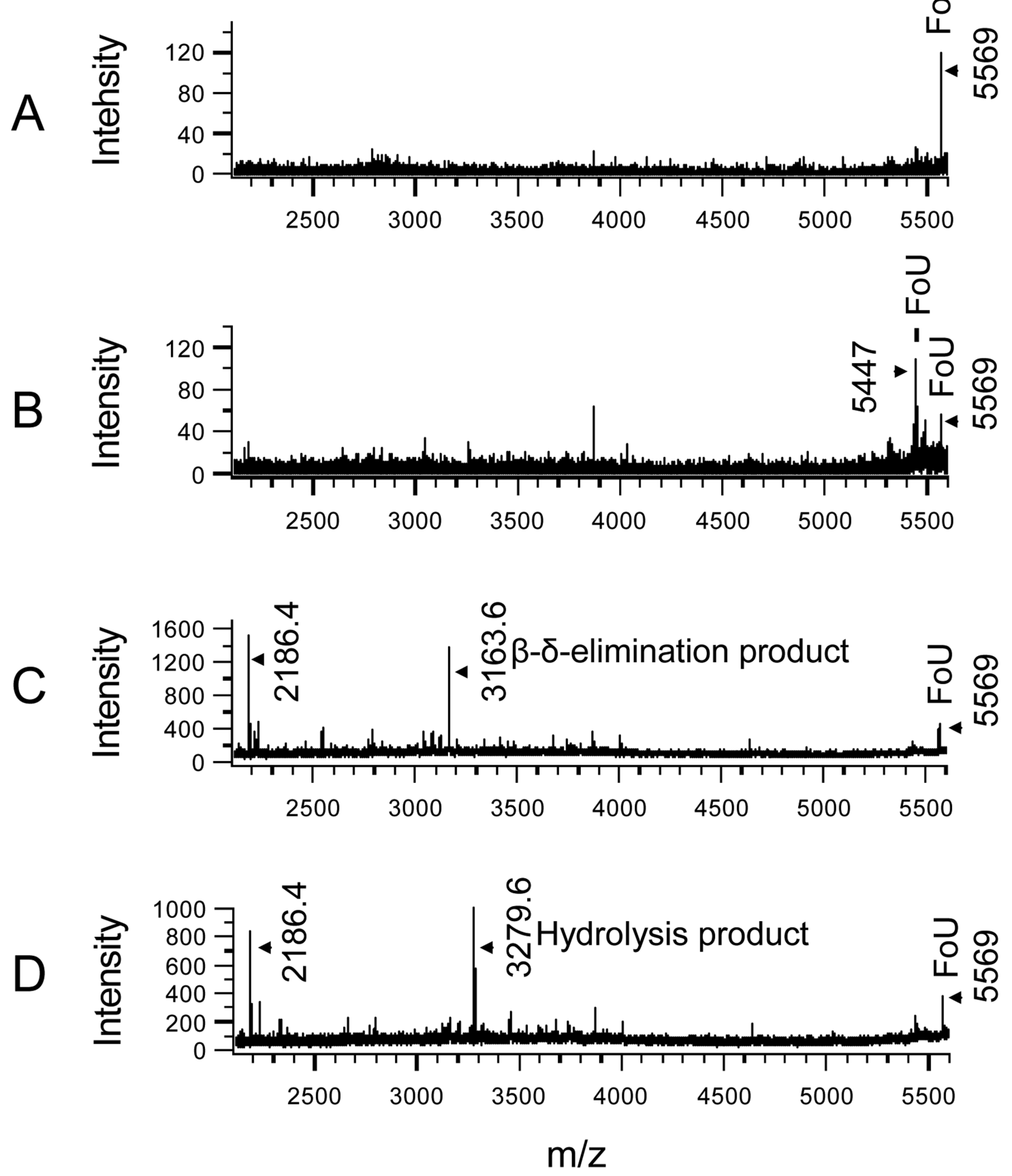

Fig. 6.

Cleavage mechanism of 18-mer oligonucleotide containing 5-formyluracil (FoU). A) Uncut FoU-containing oligonucleotide, B) FoU-containing oligonucleotide cut with hSMUG1 resulting in loss of FoU, C) FoU-containing oligonucleotide cut with Fpg, resulting in backbone cleavage via $\beta$ - $\delta$-elimination, and D) FoU-containing oligonucleotide cut by endoIII/Nth resulting in backbone cleavage and an apparent hydrolysis product. The observed monoisotopic mass values are reported to one decimal place for low molecular 
mass oligonucleotides, but for higher molecular masses, are reported as integer values due to the inherent lower resolution at high mass. 


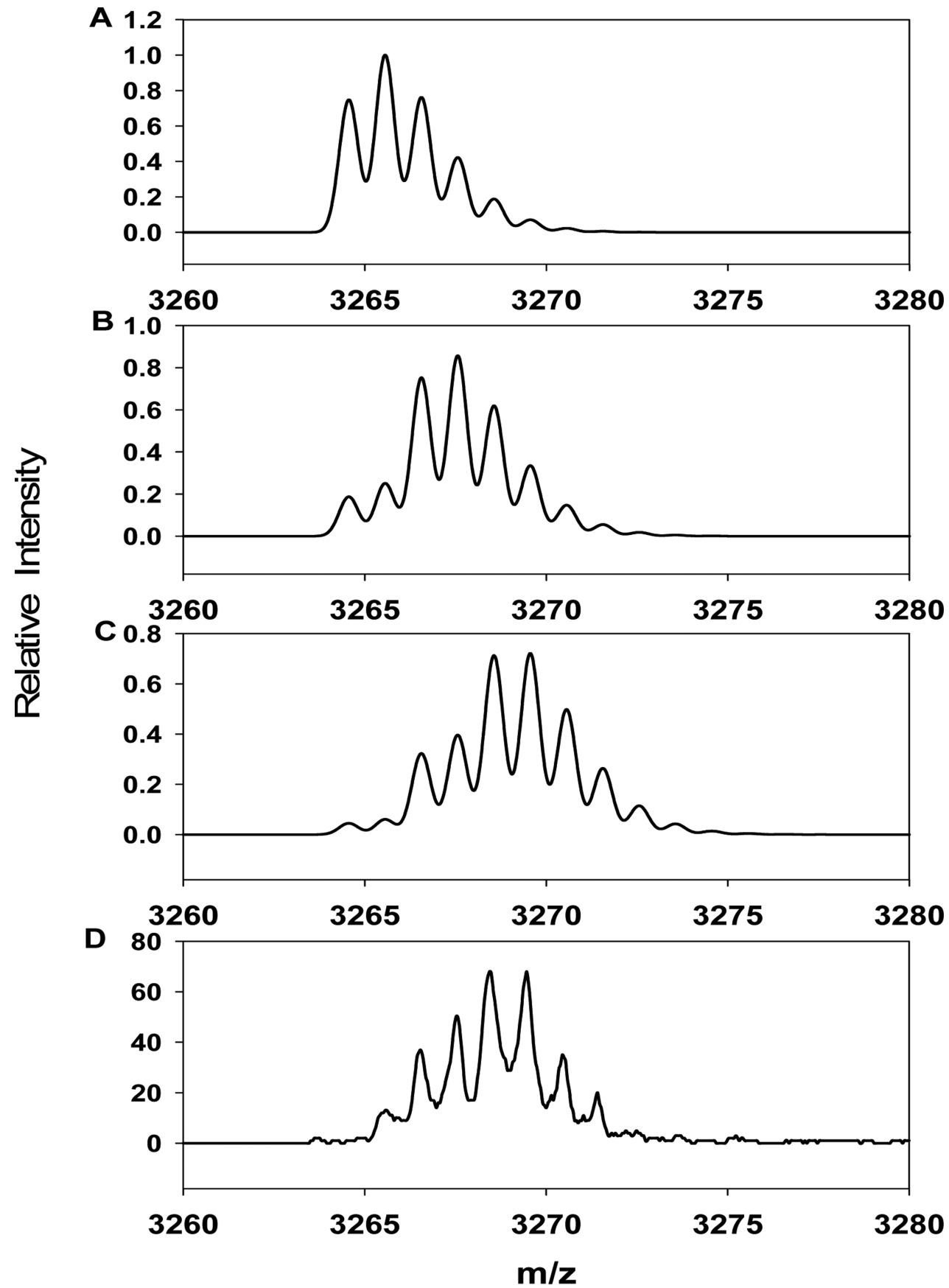

Fig. 7.

Cleavage of oligonucleotide containing 5-fluorouracil by endoIII in $25 \% \mathrm{H}_{2} 0,75 \% \mathrm{H}_{2}{ }^{18} \mathrm{O}$.

A) Simulation of mass spectrum of cleaved oligonucleotide without ${ }^{18} \mathrm{O}$-water incorporation, B) Simulation of mass spectra if one ${ }^{18} \mathrm{O}$-water is incorporated, C) Simulation if two ${ }^{18} \mathrm{O}$-water molecules are incorporated, and D) experimental mass spectrum indicating two ${ }^{18} \mathrm{O}$-water molecules are incorporated. 


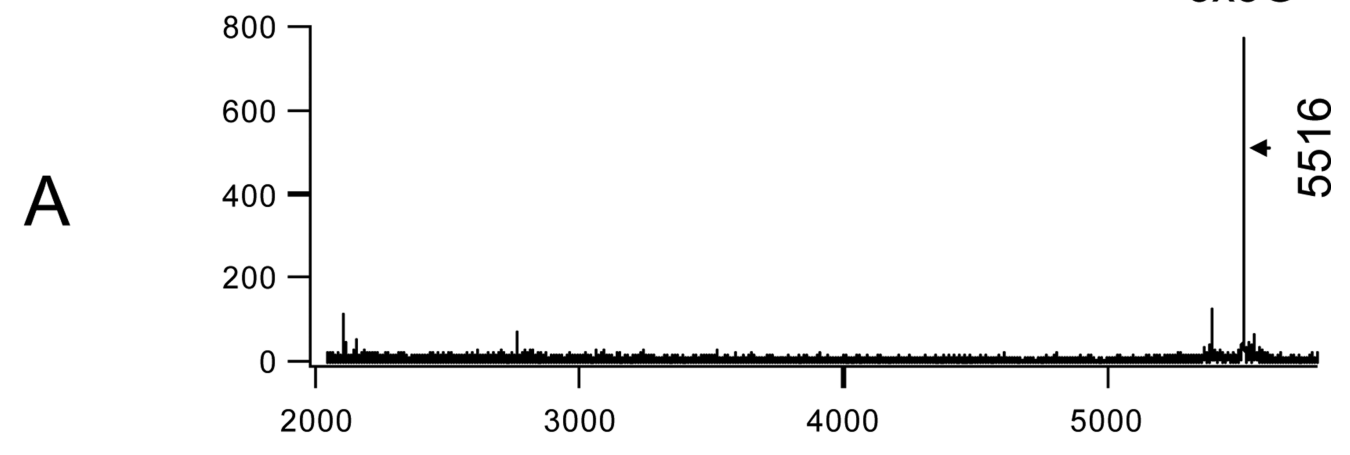

B
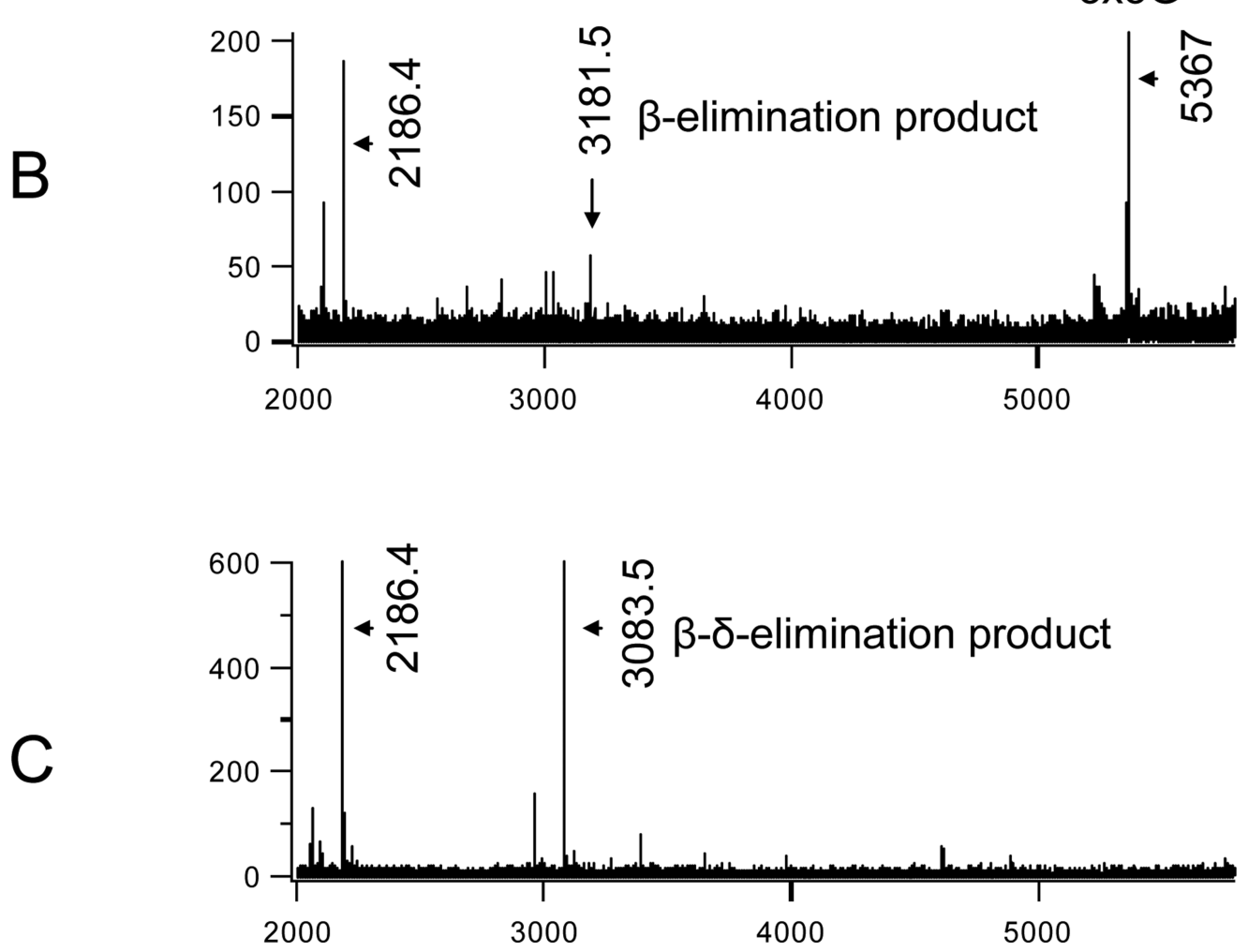

\section{$\mathrm{m} / \mathrm{z}$}

Fig. 8.

Cleavage mechanism of 18-mer oligonucleotide containing 8-oxoguanine (oxoG): A) Uncut oligonucleotide containing oxoG, B) Oligonucleotide containing oxoG cut with hOGG1, resulting in $\beta$-elimination product, and C) Oligonucleotide containing oxoG cut with Fpg, resulting in $\beta$ - $\delta$-elimination product. The observed monoisotopic mass values are reported to one decimal place for low molecular mass oligonucleotides, but for higher molecular masses, are reported as integer values due to the inherent lower resolution at high mass. 


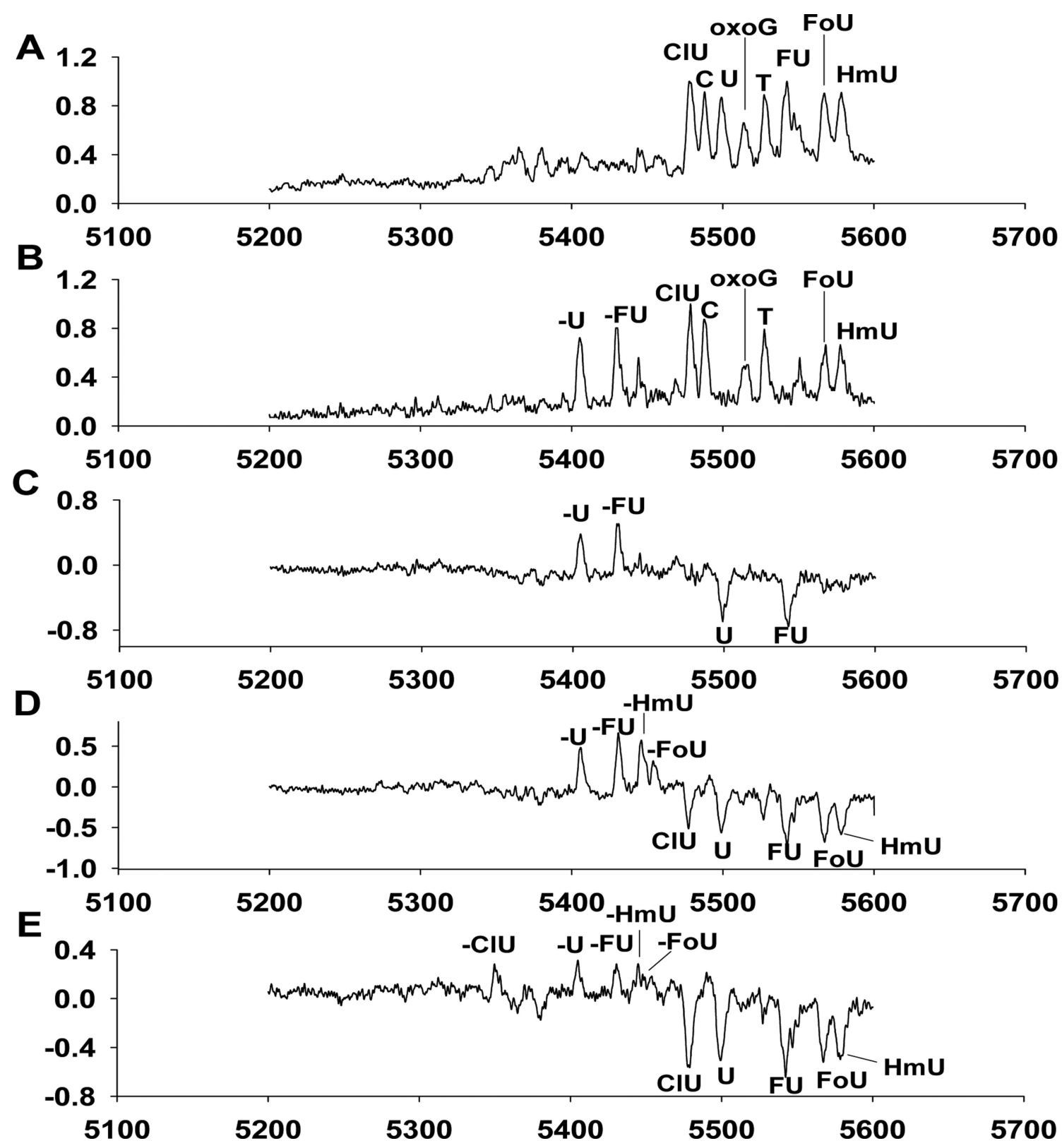

Fig. 9.

Cleavage of oligonucleotide ensemble by glycosylases. A) Mass spectra of uncut oligonucleotides, B) Mass spectrum obtained following cleavage with UNG, indicating U and FU have been cleaved, C) Difference spectrum obtained by subtracting A from B). In these difference spectra, cleavage results in negative peaks from the ensemble of original oligonucleotide, and positive peaks where cleavage has resulted in a new oligonucleotide. D) Difference spectrum obtained following cleavage with hSMUG1, E) Difference spectrum obtained following cleavage with TDG. 


\section{Enzyme attack and backbone cleavage}

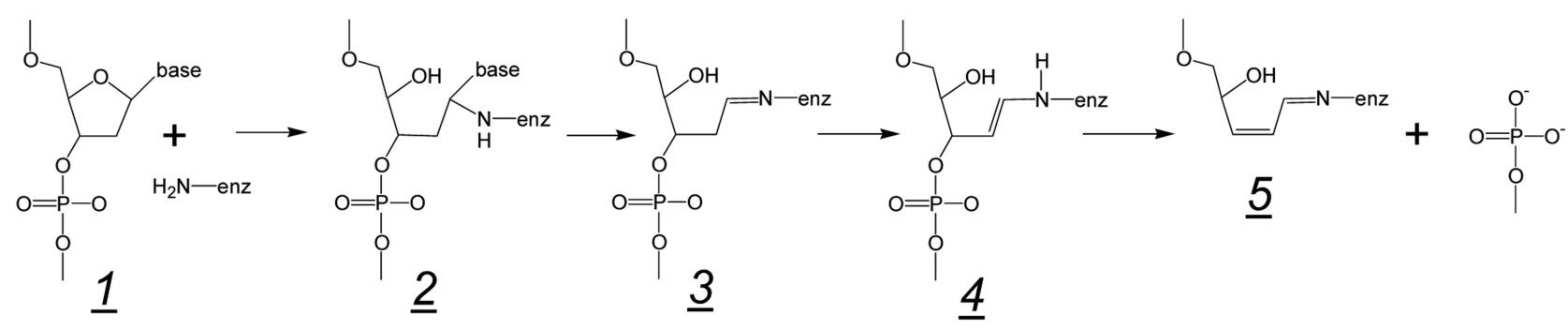

\section{Water attack and enzyme release}

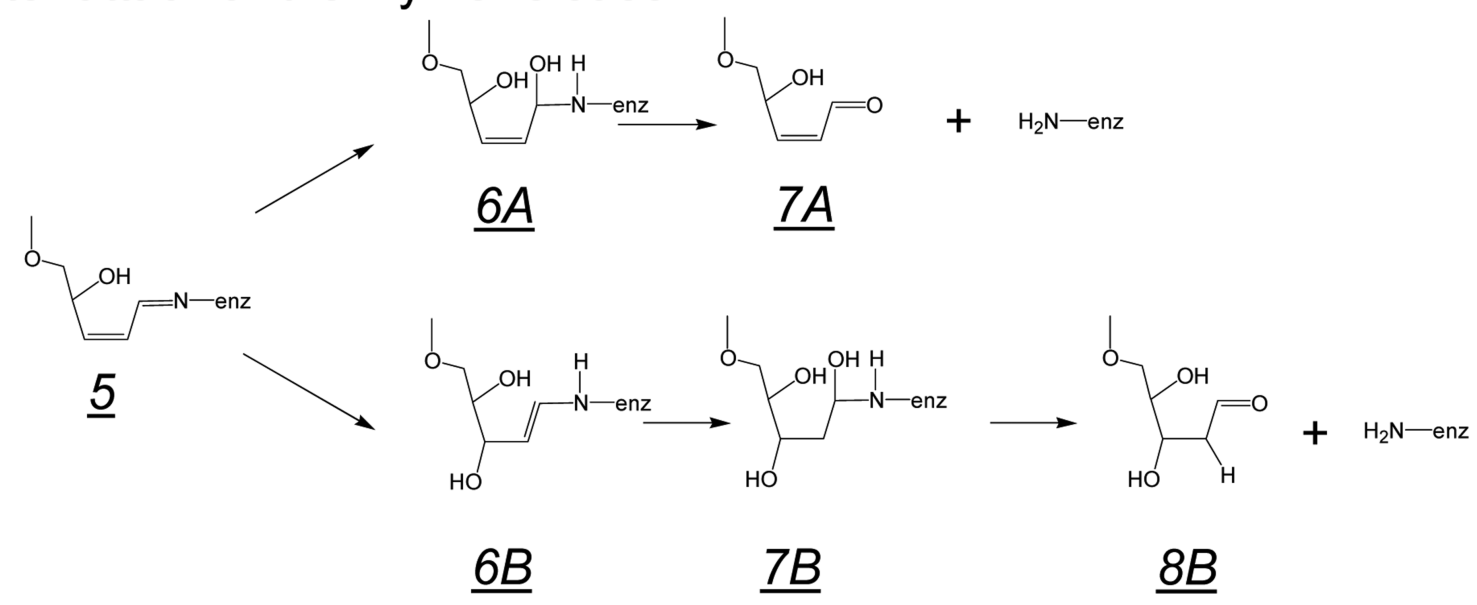

Fig. 10.

Proposed mechanism for the cleavage of an oligonucleotide by endoIII/Nth. 


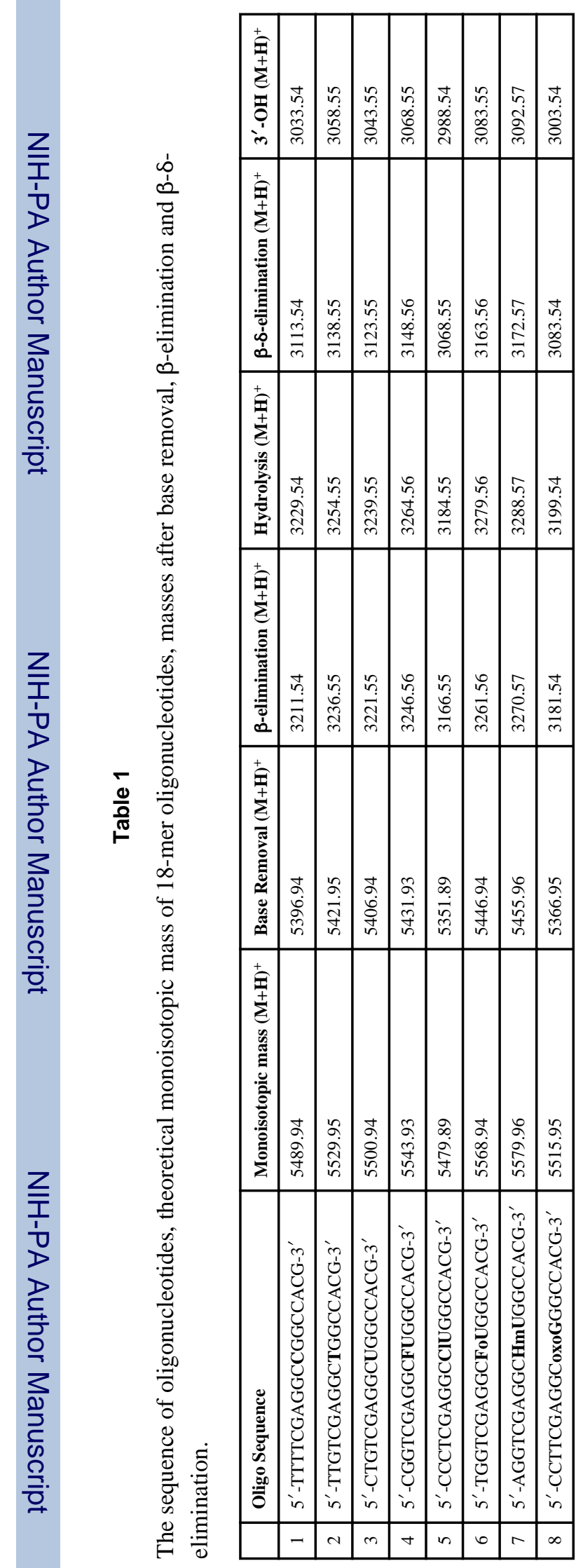

Anal Biochem. Author manuscript; available in PMC 2014 April 17. 
Table 2

The percentage cleavage of oligonucleotide substrates by each DNA glycosylase, as examined by polyacrylamide gel electrophoresis.

\begin{tabular}{|c|c|c|c|c|c|c|c|c|}
\hline Enzyme & $\mathbf{C}$ & $\mathbf{T}$ & $\mathbf{U}$ & $\mathbf{F U}$ & $\mathbf{C l U}$ & FoU & HmU & oxoG \\
\hline UNG & $<10^{-4}$ & $<10^{-4}$ & $87.7 \pm 0.6$ & $87.4 \pm 0.8$ & $7.4 \pm 0.6$ & $<10^{-4}$ & $<10^{-4}$ & $<10^{-4}$ \\
\hline MUG & $<10^{-4}$ & $<10^{-4}$ & $38.8 \pm 1.6$ & $80.4 \pm 4.1$ & $64.2 \pm 0.6$ & $23.6 \pm 0.6$ & $11.6 \pm 1.2$ & $<10^{-4}$ \\
\hline TDG & $<10^{-4}$ & $59.6 \pm 5.3$ & $82.8 \pm 4.2$ & $82.3 \pm 7.8$ & $79.4 \pm 7.6$ & $61.9 \pm 4.3$ & $63.1 \pm 3.4$ & $<10^{-4}$ \\
\hline SMUG1 & $<10^{-4}$ & $<10^{-4}$ & $87.2 \pm 2.2$ & $62.1 \pm 0.6$ & $19.7 \pm 1.2$ & $73.9 \pm 0.7$ & $71.8 \pm 1.3$ & $<10^{-4}$ \\
\hline Nth & $<10^{-4}$ & $<10^{-4}$ & $23.7 \pm 3.3$ & $88.6 \pm 2.8$ & $<10^{-4}$ & $65.0 \pm 1.2$ & $14.1 \pm 1.4$ & $<10^{-4}$ \\
\hline hOGG1 & $<10^{-4}$ & $<10^{-4}$ & $<10^{-4}$ & $<10^{-4}$ & $<10^{-4}$ & $<10^{-4}$ & $<10^{-4}$ & $82.9 \pm 1.3$ \\
\hline Fpg & $<10^{-4}$ & $<10^{-4}$ & $6.3 \pm 0.4$ & $<10^{-4}$ & $<10^{-4}$ & $54.3 \pm 5.9$ & $<10^{-4}$ & $92.1 \pm 2.1$ \\
\hline
\end{tabular}

